\title{
Heatwaves and Summer Urban Heat Islands: A Daily Cycle Approach to Unveil the Urban Thermal Signal Changes in Lisbon, Portugal
}

\author{
Ana Oliveira ${ }^{1, *(\mathbb{D})}$, António Lopes ${ }^{2} \mathbb{D}$, Ezequiel Correia ${ }^{2} \mathbb{D}$, Samuel Niza $^{1} \mathbb{D}$ and Amílcar Soares ${ }^{3} \mathbb{D}$ \\ 1 IN+ Center for Innovation, Technology and Policy Research, Instituto Superior Técnico, \\ Universidade de Lisboa, 1049-001 Lisbon, Portugal; samuel.niza@tecnico.ulisboa.pt \\ 2 Centro de Estudos Geográficos, IGOT-Instituto de Geografia e Ordenamento do Território, \\ Universidade de Lisboa, 1600-276 Lisbon, Portugal; antonio.lopes@campus.ul.pt (A.L.); \\ ezequielc@campus.ul.pt (E.C.) \\ 3 CERENA, Instituto Superior Técnico, Universidade de Lisboa, 1049-001 Lisbon, Portugal; \\ asoares@tecnico.ulisboa.pt \\ * Correspondence: anappmoliveira@tecnico.ulisboa.pt
}

check for updates

Citation: Oliveira, A.; Lopes, A.; Correia, E.; Niza, S.; Soares, A. Heatwaves and Summer Urban Heat Islands: A Daily Cycle Approach to Unveil the Urban Thermal Signal Changes in Lisbon, Portugal. Atmosphere 2021, 12, 292. https:// doi.org/10.3390/atmos12030292

Academic Editor:

Rohinton Emmanuel

Received: 17 January 2021

Accepted: 19 February 2021

Published: 24 February 2021

Publisher's Note: MDPI stays neutral with regard to jurisdictional claims in published maps and institutional affiliations.

Copyright: (c) 2021 by the authors. Licensee MDPI, Basel, Switzerland. This article is an open access article distributed under the terms and conditions of the Creative Commons Attribution (CC BY) license (https:// creativecommons.org/licenses/by/ $4.0 /)$.

\begin{abstract}
Lisbon is a European Mediterranean city, greatly exposed to heatwaves (HW), according to recent trends and climate change prospects. Considering the Atlantic influence, air temperature observations from Lisbon's mesoscale network are used to investigate the interactions between background weather and the urban thermal signal (UTS) in summer. Days are classified according to the prevailing regional wind direction, and hourly UTS is compared between HW and non-HW conditions. Northern-wind days predominate, revealing greater maximum air temperatures (up to $40{ }^{\circ} \mathrm{C}$ ) and greater thermal amplitudes (approximately $10^{\circ} \mathrm{C}$ ), and account for 37 out of $49 \mathrm{HW}$ days; southern-wind days have milder temperatures, and no HWs occur. Results show that the wind direction groups are significantly different. While southern-wind days have minor UTS variations, northern-wind days have a consistent UTS daily cycle: a diurnal urban cooling island (UCI) (often lower than $-1.0^{\circ} \mathrm{C}$ ), a late afternoon peak urban heat island (UHI) (occasionally surpassing $4.0^{\circ} \mathrm{C}$ ), and a stable nocturnal UHI $\left(1.5{ }^{\circ} \mathrm{C}\right.$ median intensity). UHI/UCI intensities are not significantly different between HW and non-HW conditions, although the synoptic influence is noted. Results indicate that, in Lisbon, the UHI intensity does not increase during HW events, although it is significantly affected by wind. As such, local climate change adaptation strategies must be based on scenarios that account for the synergies between potential changes in regional air temperature and wind.
\end{abstract}

Keywords: urban heat island; urban climate; heatwaves; local climate adaptation; mediterranean cities; Lisbon; urban thermal signal

\section{Introduction}

Lisbon, the capital of Portugal (and the corresponding largest metropolitan area), is a dense urban area positioned in the northern margin of one of the widest estuaries in Europe, the Tagus river. It is located within the Mediterranean hot-summer Mediterranean climatic region (Köppen Csa class) [1,2], but subject to the strong Atlantic influence, just a couple of kilometres to the West. The city's topography is somewhat intricate: there are several hills (so-called "city of the seven hills") and a northern plateau area, entwined by valleys throughout the city, and overall the altitudes are greater to the north (Airport's plateau and Monsanto forest hill), while the lowest altitudes correspond to the estuary margin, in the eastern and southern limits. This setting greatly determines its specific local climate $[3,4]$, particularly regarding the influence of local wind flows and land/sea breezes. Previous studies have already detected the occurrence of a temperature increase within the city center, compared to non-urbanized peripheries [5-9]. This positive thermal 
signature of urbanity is the most frequent man-made modification to local climate; it has been called the urban heat island effect (UHI) [10-12], as a reference to the city's warmer air temperature "island", compared to the non-urban surroundings. Its intensity has been shown to vary according to the urban morphology and surface characteristics: within densely built-up areas, natural cooling processes (ventilation and evapotranspiration) are reduced due to the predominance of surface sealing, the scarceness of vegetation and the obstruction of regional wind flows. Furthermore, artificial surfaces increase the urban heat storage fraction of the energy budget [10-12].

Analyzing the local UHI spatial exposure is of utmost importance, not only because this effect is known to have several negative impacts during the warmer season [13-18], but mostly because both recently observed trends and regional climate change predictions indicate that extreme heatwaves (HW) are becoming more frequent, more intense and longer in the South European region [19-25]. While the UHI effect might be considered a benefit in reducing energy demand for indoor heating during the winter, in the summer it potentially becomes an outdoor aggravation factor of thermal discomfort. In addition, it also contributes to increasing energy demand for indoor cooling during the warmer season, which is worrisome considering southern Europe's energy poverty issue [26-28]. Research results in other locations have found positive feedback between UHI intensity under those HW conditions, which means that impacts from the heat exposure in the urban setting may be be exacerbated by an abnormally greater UHI intensity, findings that have been supported by several studies $[13,18,29]$. Out of the three studies mentioned, only Ref. [13] included wind direction in the analysis; the authors have analyzed data from five stations across the metropolitan area of Athens (Greece), to show how the local UHI effect is strongly influenced by both the air temperature (positively) and regional wind direction (positively if southernly, negatively if northly). However, all these studies did consider only one urban station, as a reference, and no intra-urban differences were explored. In addition, both the Athens [13] and Paris [29] case studies relied on data from a single year (2012 and 2003, respectively). As such, their conclusions are based on a small sample of HW events.

Locally, previous studies have assessed the relation between the wind speed, out of the city (i.e., background wind), and the UHI intensity [5-9]. Those studies suggested that, under more intense wind conditions, the UHI intensity may increase due to the shelter effect of the topography and urban roughness length [7]. In addition, previous work has found that the average UHI intensities change according to the season [5-9]; a positive thermal anomaly, with a median $2.0^{\circ} \mathrm{C}$ intensity, occurs during the night, and strong UHI intensities $\left(>4.0^{\circ} \mathrm{C}\right)$ were found to be more frequent during the summer, when the impact is more likely to be harmful. However, those studies focused on the typical seasonal patterns of the UHI effect, and its response to extreme temperature events was not assessed in detail. With this research, in addition to previous analysis, the summer and HW conditions are further explored by detailing the UHI response to background weather conditions, particularly air temperature and prevailing wind direction.

Given the urgency of adapting to a climate change scenario wherein HW events will, very likely, become more frequent, lengthy and intense $[19,30,31]$ ( $a$ trend that has indeed been already detected in the past 20 years), in this study, summer (June, July, August, and September) hourly air temperature measurements registered by the CEG/IGOT (Centre of Geographical Studies-Institute of Geography and Spatial Planning) mesoscale network during an 11-year period (2004 to 2015) were used to identify the interactions between the regional reference weather conditions and the local UHI intensity. Particularly, this study adds to the findings included in Lisbon's 2020 project "Cartography for Thermal Vulnerability-Mapping the effects of heatwaves in Lisbon" (translation from the Portuguese original "Cartografia de Vulnerabilidade Térmica-Mapeamento dos efeitos das ondas de calor em Lisboa, face às projeções climáticas") $[8,32,33]$ carried out by the Lisbon Municipality, by developing a sub-daily UHI analysis approach. 
In fact, most urban climate studies focusing on the urban canopy layer UHI (i.e., between the surface and roof level) measure its magnitude on a daily basis, using the $\Delta \mathrm{T}_{\mathrm{u}-\mathrm{r}}$ definition (i.e., the " $\Delta \mathrm{T}_{\mathrm{u}-\mathrm{r}}=\mathrm{Tu}-\mathrm{Tr}$ " equation) to depict the difference between the maximum air temperature within the urban area, and a reference temperature of the nonurban surroundings [12]. This temporal resolution is, however, insufficient to disclose the full picture of the daily cycle of the urban thermal response to the input energy it receives and stores [34]. Several studies have analyzed the UHI's sub-daily changes, showing that it is mostly a nocturnal phenomenon; during the day, the UHI is often replaced by an urban cooling island (UCI) [34-36]. In Lisbon, this day-night phase change of the UHI (negative to positive) has been documented previously [5-9]; however, its variations according to heatwave conditions or regional wind direction were not assessed.

Hereinafter referred to as the urban thermal signal (UTS), the hourly intensities and rate of change of the urban air temperature difference (between the urban and nonurban sites, on an hourly basis) are not always positive in Lisbon, as opposed to the UHI magnitude concept, which, by definition, quantifies the maximum (and hence positive) urban thermal anomaly. In this study, typical summer UTS daily cycles are identified, according to different types of background/regional near-surface wind conditions. In particular, two hypotheses are tested: (i) both the summer UHI intensity (maximum, daily) and the UTS daily cycle vary significantly, according to the prevailing regional wind flow direction; and (ii) both the UHI intensity and UTS daily cycle do not significantly change during heatwave events.

\section{Materials and Methods}

The urban air temperature measurements (i.e., $\mathrm{Tu}$ ) were registered by the mesoscale observation network of the academic institution CEG/IGOT. The network was established in 2004, including 9 temperature/relative humidity probes (see Figure 1) provided with Tiny Tag Plus (Gemini) data loggers $[5-7,37]$. The devices were installed on public lighting poles, at $3.5 \mathrm{~m}$ height, inside radiation protection shields, and their placements followed the advice given by T.R. Oke, as a consultant for an ongoing urban climatology project at the time [5-7]. Air temperature and humidity observations were taken every $15 \mathrm{~min}$, and the network remained in operation until 2015 [5-7]. The sensors were placed in strategic sites to sample Lisbon's land cover and geographical heterogeneity. In 2007, the first results from the mesoscale network were published [37]. To ensure data quality, the devices were subject to testing routines every 2 to 3 years, and no meaningful measurement differences were detected [5-7]. Figure 1 and Table 1 show the list of sites, as well as their main geographical and land cover characteristics, such as: (i) distances to the riverside and Atlantic coast, as per the Euclidian distance algorithm implemented in ArcGISv13.1; (ii) local climate zone classes (LCZ) [37,38]; and (iii) altitude and topographic exposure indices of the four main quadrants (north, south, east and west), obtained from the Global Digital Elevation Model Version 3 (DEM) of the Advanced Spaceborne Thermal Emission and Reflection Radiometer (ASTER) [39-41].

To be comparable with previous studies, the local Airport meteorological station was selected as the non-urban air temperature reference site (i.e., Tr), and its dataset of meteorological observations was extracted from the Integrated Surface Database-Global Hourly observations (ISD/GH), available at the National Centers for Environmental Information of the National Oceanic and Atmospheric Administration (NOAA) [42]. 
Table 1. List and characterization of the measurement sites

\begin{tabular}{|c|c|c|c|c|c|c|c|}
\hline $\begin{array}{c}\text { Name } \\
\text { (Acronym) }\end{array}$ & & $\begin{array}{l}\text { Latitude } \\
\text { (Degrees) }\end{array}$ & $\begin{array}{l}\text { Longitude } \\
\text { (Degrees) }\end{array}$ & $\begin{array}{l}\text { Elevation } \\
\quad(\mathrm{m})\end{array}$ & $\begin{array}{c}\text { Tagus River } \\
\text { Distance } \\
(\mathbf{k m})\end{array}$ & $\begin{array}{c}\text { Western Atlantic } \\
\text { Coast Distance }(\mathbf{k m})\end{array}$ & $\begin{array}{c}\mathrm{LCZ} \\
\text { (Class) }\end{array}$ \\
\hline Airport ${ }^{1}$ & AIR & +38.7649 & -9.1325 & +86.6 & 4.0 & 16.1 & $\mathrm{E}$ \\
\hline Monsanto $^{2}$ & $\mathrm{MON}$ & +38.7182 & -9.1992 & +179.0 & 2.3 & 8.0 & A \\
\hline Carnide $^{2}$ & CAR & +38.7650 & -9.1817 & +111.0 & 6.5 & 12.8 & 5 \\
\hline Alcântara $^{2}$ & ALC & +38.7194 & -9.1750 & +28.4 & 2.1 & 9.8 & $\mathrm{E}$ \\
\hline C. de Ourique ${ }^{2}$ & OUR & +38.7140 & -9.1693 & +85.6 & 1.4 & 9.9 & 2 \\
\hline Bairro Alto 2 & BAL & +38.7156 & -9.1448 & +73.81 & 1.0 & 11.9 & 2 \\
\hline Saldanha $^{2}$ & SAL & +38.7342 & -9.1447 & +94.7 & 2.8 & 13.1 & 2 \\
\hline Restauradores $^{2}$ & RES & +38.7163 & -9.1420 & +27.0 & 1.0 & 12.2 & 2 \\
\hline P. das Nações ${ }^{2}$ & PNA & +38.7547 & -9.0949 & +8.0 & 0.1 & 18.2 & 1 \\
\hline Belém $^{2}$ & BEL & +38.6937 & -9.2135 & +6.2 & 0.1 & 5.2 & 6 \\
\hline
\end{tabular}

${ }^{1}$ Reference non-urban station for urban heat island (UHI) intensity calculation, source: Integrated Surface Database-Global Hourly (ISD/GH), station id: 853609 [42]. ${ }^{2}$ Institute of Geography and Spatial Planning (IGOT) network. Source: Centre of Geographical Studies-Institute of Geography and Spatial Planning (CEG/IGOT) network [5].

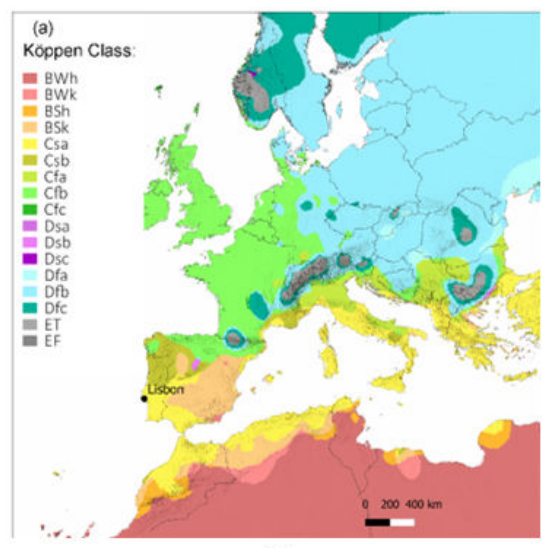

(a)

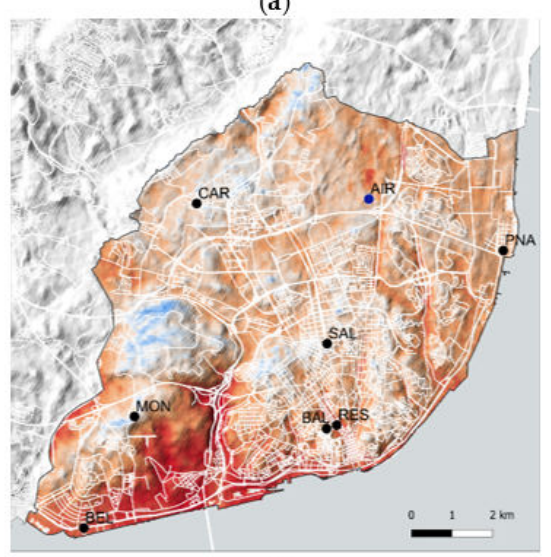

(c)

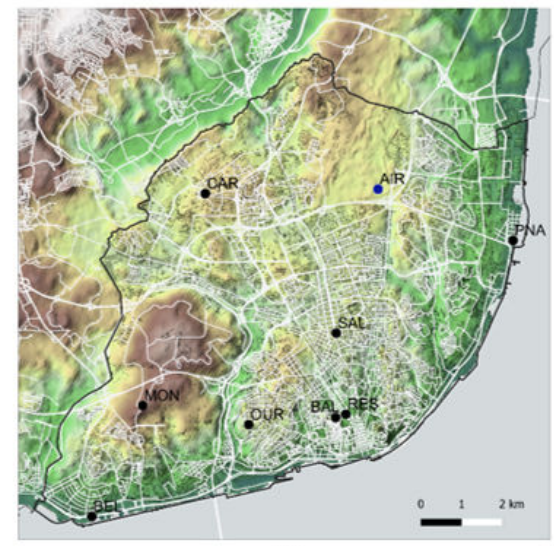

(b)

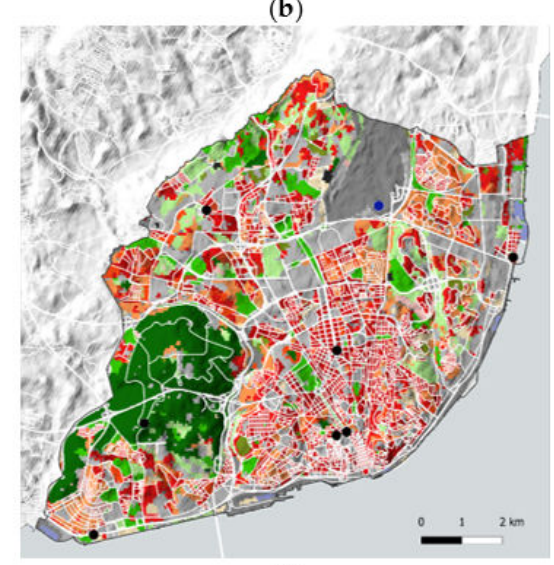

(d)

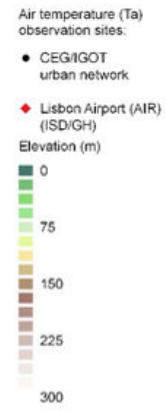

300

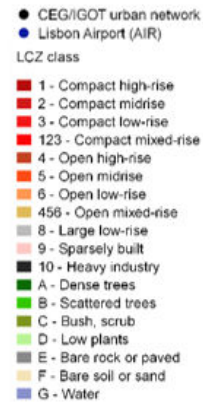

F. Bare rock or paved
F. Bare soll or sand

Figure 1. Air temperature (Ta) observation sites used in this study: Belém (BEL), Monsanto (MON), Alcântara (ALC), Campo de Ourique (OUR), Bairro Alto (BAL), Carnide (CAR), Saldanha (SAL), Restauradores (RES), Parque das Nações (PNA) and Lisbon Airport (AIR). Base layers are: (a) Lisbon location over Köppen classification [1,2,43]; (b) Lisbon CEG/IGOT and AIR over terrain elevation [39]; (c) average north to northwest topographic exposure [40,41]; and (d) LCZ class [37,38]. 
The methodology applied in the analysis followed three data preparation steps: (i) classifying summer days, according to the prevailing regional near-surface wind direction measured at the Lisbon Airport meteorological station (i.e., the city's background wind conditions); (ii) classifying summer days as either heatwave (HW) or non-heatwave (non-HW) days, based on the excess heat factor method [44,45]; (iii) quantifying and characterizing the daily cycle of the UTS of each wind direction-based subset, at Lisbon's city center.

For the wind direction-based classification, each hourly observation was classified according to the prevailing octant directions, as shown in Table 2. Each day was considered as belonging to a given class, whenever the corresponding cardinal or intercardinal wind direction persists during, at least, $80 \%$ of the day. The secondary intercardinal wind direction hours were included in the adjacent octant direction with the greatest frequency. For example, north-north-west wind hours may be included in either the north ("N") or northwest ("NW") class, depending on which of these two has the highest frequencies during that day. A special case of variable but north-dominant wind days ("N var") was considered due to the considerable number of days that, although having less than $80 \%$ hours of northern wind, have no (or very few) hours with east, south or west wind flows ("E", "S", and "W", respectively). Actual "Varying" wind days were considered whenever the previous conditions were not applicable, i.e., wind direction observations spread from 0 to $360^{\circ}$, throughout the day.

Table 2. Regional near-surface wind direction-based classification.

\begin{tabular}{ccccc}
\hline $\begin{array}{c}\text { Wind Direction-Based Days } \\
\text { Classification }\end{array}$ & Acronym & $\begin{array}{c}\text { Octant Limits } \\
\text { (Secondary Intercardinal Wind Directions) } \\
\text { Minimum }\end{array}$ & $\begin{array}{c}\text { Frequency Criteria } \\
\text { Maximum }\end{array}$ & n.a. \\
(Hours per Day)
\end{tabular}

In addition, the correspondence between synoptic weather conditions and local wind direction classes was investigated. Mean sea level pressure data were retrieved from the gridded ERA 5 reanalysis (spatial resolution: $25 \mathrm{~km}$ ), and subjected to the JenkinsonCollison (JC) synoptic weather type classification system, as per Ref. [46], implemented through the "jcext" package [47] in the R environment [48]. The output of the R-based package is a time series of daily classified data, according to a set of 27 total synoptic weather types (see Table 3): 2 major vorticity types (anticyclonic and cyclonic), 8 major directional types (cardinal and primary intercardinal), and 16 combination hybrid types (combinations of direction and vorticity). An additional "Unclassified" type corresponds to weak or chaotic flow [46].

To calculate the frequency of each (JC) type, per local wind direction class, the scheme proposed by Ref. [39] was followed, which entails summarizing the frequency results according to the 11 major weather types mentioned. Thus, while each day classified as a "pure" JC type counts as one case, each "hybrid" weather type day is accounted for with a weight of $1 / 2$ or $1 / 3$ of a case, whenever there is a two or three major weather type combination, respectively (e.g., a day classified as AN counts as $1 / 2$ of the vorticity $A_{\text {JC }}$ class, and $1 / 2$ of the directional $\mathrm{N}_{\mathrm{JC}}$ class). As a result, only the 11 major synoptic weather types are retained. 
Table 3. Jenkinson-Collison major synoptic weather types ${ }^{1}$.

\begin{tabular}{|c|c|c|c|c|}
\hline \multicolumn{3}{|c|}{ Major Synoptic Weather Types } & \multicolumn{2}{|c|}{$\begin{array}{c}\text { Hybrid Synoptic } \\
\text { Weather Types }\end{array}$} \\
\hline $\begin{array}{l}\text { Vorticity } \\
\text { (acronym) }\end{array}$ & $\begin{array}{l}\text { Directional } \\
\text { (acronym) }\end{array}$ & $\begin{array}{l}\text { Unclassified } \\
\text { (acronym) }\end{array}$ & $\begin{array}{l}\text { Anticyclonic } \\
\text { (acronym) }\end{array}$ & $\begin{array}{l}\text { Cyclonic } \\
\text { (acronym) }\end{array}$ \\
\hline Anticyclonic $\left(\mathrm{A}_{\mathrm{JC}}\right)$ & North $\left(\mathrm{N}_{\mathrm{JC}}\right)$ & Unclassified ( $\left.\mathrm{U}_{\mathrm{JC}}\right)$ & AN & $\mathrm{CN}$ \\
\hline \multirow[t]{10}{*}{ Cyclonic $\left(\mathrm{C}_{\mathrm{JC}}\right)$} & Northeast $\left(\mathrm{NE}_{\mathrm{JC}}\right)$ & & ANE & CNE \\
\hline & East $\left(\mathrm{E}_{\mathrm{JC}}\right)$ & & $\mathrm{AE}$ & $\mathrm{CE}$ \\
\hline & Southeast $\left(\mathrm{SE}_{\mathrm{JC}}\right)$ & & ASE & CSE \\
\hline & South $\left(\mathrm{S}_{\mathrm{JC}}\right)$ & & AS & CS \\
\hline & Southwest $\left(\mathrm{SW}_{\mathrm{JC}}\right)$ & & ASW & CSW \\
\hline & West $\left(\mathrm{W}_{\mathrm{JC}}\right)$ & & $\mathrm{AW}$ & $\mathrm{CW}$ \\
\hline & Northwest $\left(\mathrm{NW}_{\mathrm{JC}}\right)$ & & ANW & $\mathrm{CNW}$ \\
\hline & & & $\mathrm{A}+\mathrm{N}+\mathrm{E}$ & $\mathrm{C}+\mathrm{E}+\mathrm{N}$ \\
\hline & & & & $C+E+S$ \\
\hline & & & & $\mathrm{C}+\mathrm{S}+\mathrm{W}$ \\
\hline
\end{tabular}

${ }^{1}$ Adapted from [47].

To identify the hourly changes in the urban temperature, for each local wind directionbased subset of days, the time-series of the hourly UTS intensity is calculated as per Equation (1):

$$
\mathrm{UTS}=\mathrm{Tu}_{(\mathrm{h})}-\mathrm{Tr}_{(\mathrm{h})}
$$

where $\mathrm{Tu}_{(\mathrm{h})}$ refers to the mean hourly air temperature observed in each urban site of the IGOT's network, and $\operatorname{Tr}_{(\mathrm{h})}$ is the mean hourly air temperature observed at the Lisbon Airport meteorological station. The resulting time-series was subject to empirical distribution analysis, by calculating representative hourly percentiles, to assess each site's UTS intensity daily profiles, namely the following: median (UTS50p), and lower/upper 10th and 90th percentile extremes (UTS10p and UTS90p, respectively).

The daily cycle of the UTS was also reclassified into different stages, according to the signal (positive versus negative) and slope of the hourly UTS rate of change. Since the UTS domain is discrete (hourly intervals), this UTS rate of change, or $\triangle$ UTS, depicts the UTS trend over a two-hour period, calculated as the discrete numerical approximation of the first-order derivative (finite difference method) as per Equation (2), allowing us to identify numerically which periods have an almost stationary UTS, or an increasing/ decreasing intensity:

$$
\Delta \mathrm{UTS}=d \mathrm{UTS} / d \mathrm{t}
$$

where $\mathrm{t}$ is time, in hours.

To compare HW and non-HW days, the excess heat factor (EHF) definition was adopted, due to it being well documented as an appropriate health-related index [44,45]. In this study, the 90th percentile of the daily mean temperature at the airport reference site was considered for the EHF threshold calculation. Airport air temperature data, from the 1981 to 2010 period, were used to calculate each day-of-the-year (DOY) 90th percentile, and a 15-day moving average smoothing function was applied. According to the EHF method, the first step is to calculate each day's excess heat index significance $\left(\mathrm{EHI}_{\mathrm{sig}}\right)$, which means that a long-term thermal anomaly occurs whenever the average of the mean air temperature for 3 days surpasses the 90th percentile of the corresponding DOY. Furthermore, the $\mathrm{EHI}_{\text {sig }}$ is multiplied by the difference between the same 3-day average mean temperature and that of the last 30 days, to account for the short-term excess heat index acclimatization ( $\left.\mathrm{EHI}_{\text {accl }}\right)$, whenever this latter index is positive. The resulting index is measured in ${ }^{\circ} \mathrm{C}^{2}$, and days of positive EHF values indicate an HW event of at least three consecutive days. Detailed explanations of the EHF calculation method can be found in $[44,45]$. 


\section{Results}

\subsection{Variability of the Urban Thermal Signal (UTS) Daily Cycle, as a Function of Prevailing} Wind Direction

The time series characterization of each local wind direction-based group is shown in Table 4, namely the number of hourly observations (and days) and mean meteorological conditions. It should be noted that these wind direction-based classes refer to the conditions in the windward non-urban reference site, Lisbon Airport, and thus do not represent interurban wind patterns, but only the regional near-surface flows. Furthermore, Figure 2 depicts the frequency of the JC synoptic weather types, per local wind direction class, and Figure 3 shows the daily cycles of the Airport's near-surface air temperature, wind speed and wind roses, per each wind-class group (besides the absence of "SE" days, plots corresponding to "E" and "NE" were also excluded due to low statistic relevance, given that only 1 and 2 days were classified as such, respectively). In addition, the UTS daily cycle plots in Figure 3 indicate the intensity of the urban thermal anomaly observed at the city center (i.e., at Restauradores, RES site in Figure 1).

Table 4. Characterization of the temperature and wind observations at the airport reference station during prevalent summer and heatwave conditions (2005-2014).

\begin{tabular}{|c|c|c|c|c|c|c|c|c|c|}
\hline \multirow{2}{*}{ Wind Direction Class } & \multirow{2}{*}{$\begin{array}{c}\text { Total Number of } \\
\text { Observations } \\
\text { (Hours (Days)) }\end{array}$} & \multicolumn{3}{|c|}{$\begin{array}{l}\text { Daily Average } \\
\text { Near-Durface Air } \\
\text { Temperature (Ta) }\end{array}$} & \multicolumn{2}{|c|}{$\begin{array}{c}\text { EHF-Based } \\
\text { Heatwaves (HW) }\end{array}$} & \multicolumn{3}{|c|}{$\begin{array}{l}\text { Daily Average Wind } \\
\text { Speed (Ws) }\end{array}$} \\
\hline & & $\begin{array}{l}\text { Mean } \\
\left({ }^{\circ} \mathrm{C}\right)\end{array}$ & $\begin{array}{l}\text { Max. } \\
\left({ }^{\circ} \mathrm{C}\right)\end{array}$ & $\begin{array}{l}\text { Min. } \\
\left({ }^{\circ} \mathrm{C}\right)\end{array}$ & $\begin{array}{l}\text { Observations } \\
\text { (Hours (Days)) }\end{array}$ & $\begin{array}{l}\text { Daily Average } \\
\text { EHF Intensity } \\
\qquad\left({ }^{\circ} C^{2}\right)\end{array}$ & $\begin{array}{l}\text { Mean } \\
(\mathrm{m} / \mathrm{s})\end{array}$ & $\begin{array}{l}\text { Max. } \\
(\mathrm{m} / \mathrm{s})\end{array}$ & $\begin{array}{l}\text { Min. } \\
(\mathrm{m} / \mathrm{s})\end{array}$ \\
\hline Max.Varying & $3312(138)$ & 23.3 & 40.0 & 13.9 & $264(11)$ & 8.7 & 3.6 & 5.7 & 1.5 \\
\hline $\mathrm{N}$ var & $3480(145)$ & 23.4 & 37.8 & 13.9 & 480 (20) & 3.9 & 4.3 & 6.5 & 2.4 \\
\hline $\mathrm{N}$ & $7488(312)$ & 21.7 & 37.8 & 13.9 & 408 (17) & 6.3 & 6.5 & 9.0 & 3.8 \\
\hline NW & $1776(74)$ & 21.2 & 32.8 & 13.9 & $0(0)$ & - & 5.4 & 6.9 & 3.4 \\
\hline W & $528(22)$ & 20.5 & 27.8 & 15.0 & $24(1)$ & 1.0 & 5.2 & 6.6 & 3.3 \\
\hline SW & 408 (17) & 21.2 & 37.2 & 16.1 & $0(0)$ & - & 4.9 & 5.9 & 2.6 \\
\hline$S$ & $168(7)$ & 20.9 & 25.0 & 17.2 & $0(0)$ & - & 6.4 & 7.5 & 3.3 \\
\hline SE & $0(0)$ & - & - & - & $0(0)$ & - & - & - & - \\
\hline $\mathrm{E}$ & $24(1)$ & 20.0 & 23.9 & 17.2 & $0(0)$ & - & 6.1 & 6.2 & 3.6 \\
\hline $\mathrm{NE}$ & $48(2)$ & 21.5 & 27.2 & 17.8 & $0(0)$ & - & 3.5 & 5.3 & 2.4 \\
\hline Total & $17,232(767)$ & & & & $1176(49)$ & & & & \\
\hline
\end{tabular}

Out of 767 days (i.e., 17,232 hourly observations), 312 belong to the north (" $\mathrm{N}$ ") wind direction-based class, representing almost half of the observations. Likewise, the northvariable ("N var") wind-class represents an additional 145 days- these are days wherein the north component also prevails (see wind roses in Figure 3), but hourly observations span from $270^{\circ}$ to $90^{\circ}$.

"Varying" wind days also account for a very significant proportion of cases (138, out of 767); these represent days during which the wind direction spanned between more than two adjacent cardinal directions throughout the day, and thus are characterized by heterogenous wind direction circumstances. Regardless, the "Varying" group wind rose, in Figure 3, shows the importance of the northern wind component, which explains that these days have, partially, conditions that are similar to those of the " $\mathrm{N}$ " and " $\mathrm{N}$ var" groups.

Both " $\mathrm{N}$ " and "N var" groups reveal similar daily cycles, characterized by greater daily maximum air temperatures (Tx), ranging from 24 to $34^{\circ} \mathrm{C}$ (maximum of $\operatorname{Tr} 10$ th and 90th percentiles, $\operatorname{Tr} 10 \mathrm{p}$ and $\operatorname{Tr} 90 \mathrm{p}$, respectively), which is at least $4{ }^{\circ} \mathrm{C}$ warmer than the median Tx during south ("S") or southwest ("SW") wind days. "N" and "N var" days have also greater thermal amplitudes, which reach up to $10^{\circ} \mathrm{C}$, compared to the approximately $3{ }^{\circ} \mathrm{C}$ day-night differences that can be observed during " $\mathrm{S}$ ", "SW" or even western ("W") conditions. The wind speed (Ws) hourly curves are also different between groups, with peak Ws values occurring during the late afternoon hours, in " $\mathrm{N}$ " and " $\mathrm{N}$ var" days, and during the midday hours in "S" and "SW" days. 


\section{Non-heatwave days (JJAS, 2005-2014)}
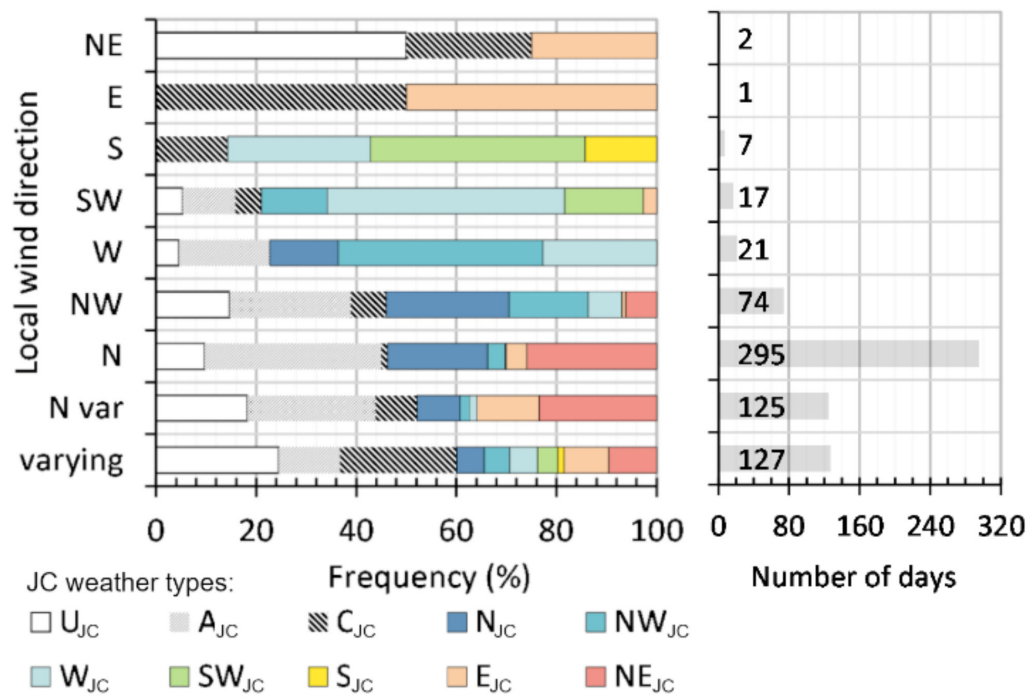

(a)

Heatwave days (JJAS, 2005-2014)

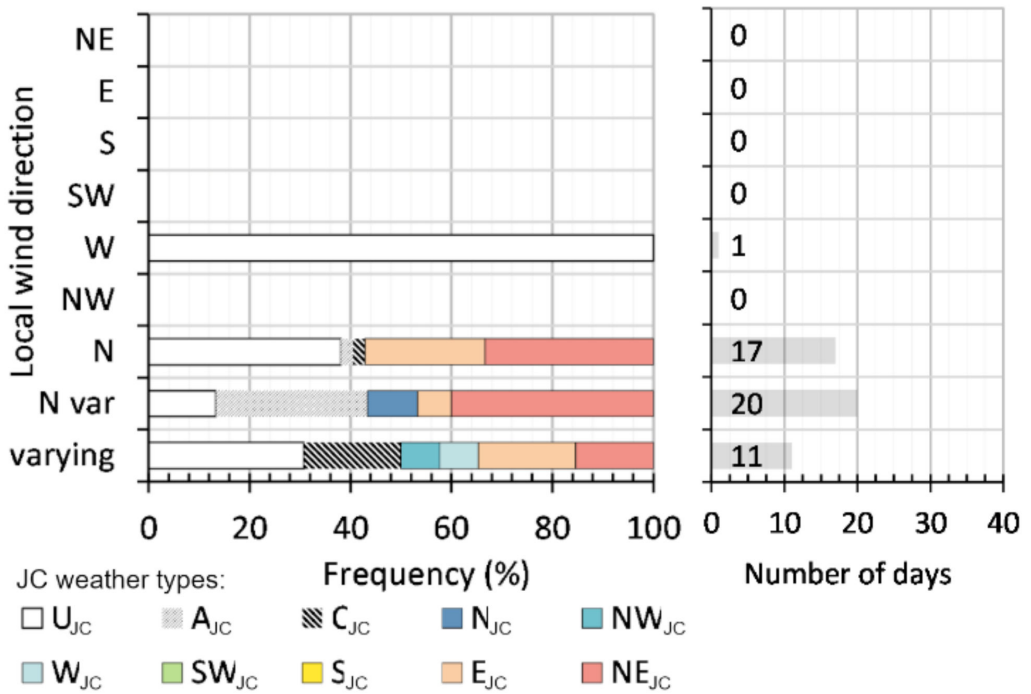

(b)

Figure 2. Frequency plots of Jenkinson-Collison (JC) weather types and the number of days, per local wind direction class and heatwave (HW)/non-heatwave (non-HW) days: (a) out of 669 non-HW days, local northern wind days ("N" or "N var" classes) are predominant (295 and 125 days, respectively), and show the greatest percentages of anticyclonic $\left(\mathrm{A}_{\mathrm{JC}}\right)$ and northeast $\left(\mathrm{NE}_{\mathrm{JC}}\right)$ synoptic flows; and (b) out of $49 \mathrm{HW}$ days, 37 are also characterized by northern winds, and the proportion of $\mathrm{NE}_{\mathrm{JC}}$ conditions is greater. The JC weather types are described in Table 3. 


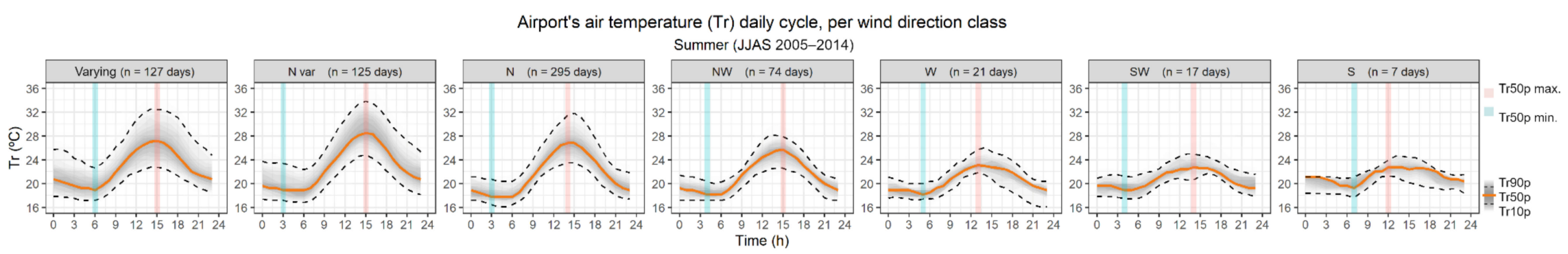

Urban Thermal Signal (UTS) daily cycle in Lisbon's city centre site, per wind direction class
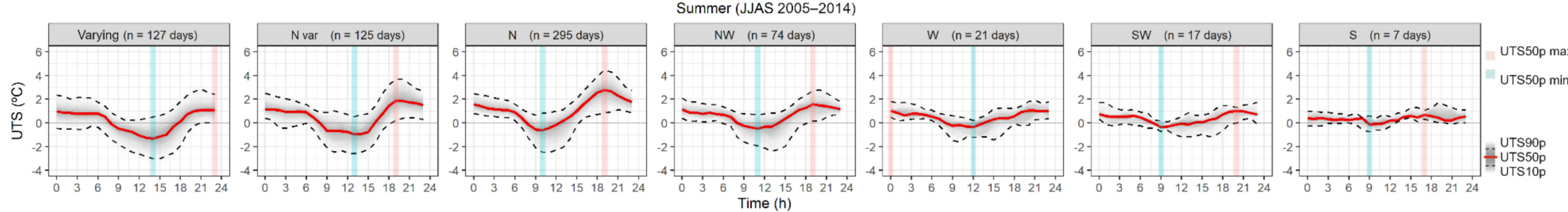

Airport's wind speed (Ws) daily cycle, per wind direction class
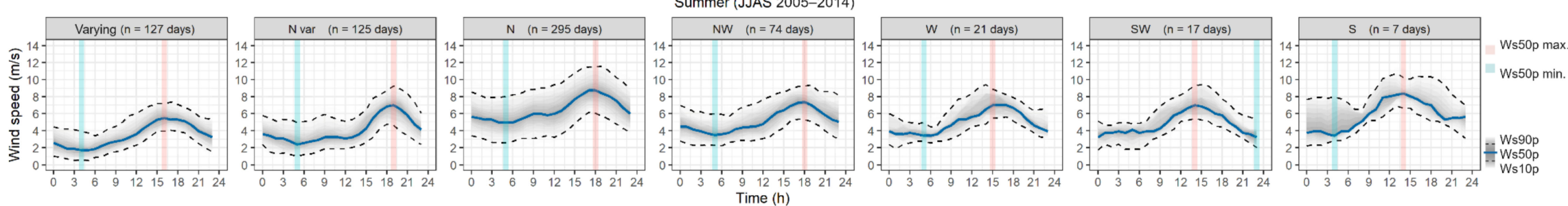

Airport's wind rose plots, per wind direction class

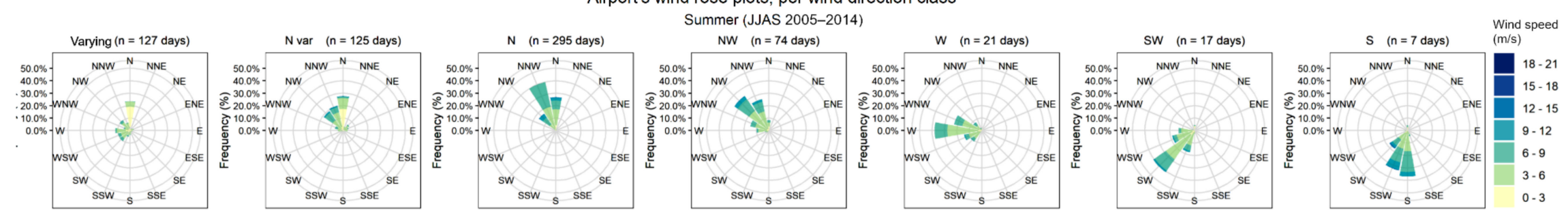

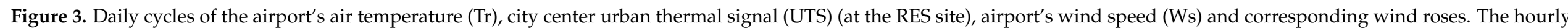
statistical distribution curves represent the 10th, 50th and 90th percentiles (10p, 50p and 90p, respectively), per wind direction-based class. 
The resulting UTS daily cycle is affected by these differences: while " $\mathrm{N}$ ", "N var", "NW" and "Varying" days are characterized by a median $1.5^{\circ} \mathrm{C}$ nocturnal UHI intensity (from approximately 11 p.m. to 6 a.m.) in Lisbon's city center, only the "N" and "N var" days reveal the existence of a late afternoon UHI peak intensity that frequently ranges from 2.0 to $3.0^{\circ} \mathrm{C}$ (median late afternoon UHI intensity), but sometimes surpasses $4.0^{\circ} \mathrm{C}$ (see the " $\mathrm{N}$ " class UTS 90th percentile curve, i.e., UTS90p). By contrast, ' $\mathrm{W}$ ', "SW" and "S" days have overall milder air temperature conditions, lower thermal amplitudes, and are characterized by frequently lower than $1.0^{\circ} \mathrm{C}$ UHI intensities, at the city center, and only very slow and slight changes in the UTS occur throughout the day.

Regarding extreme temperature events, out of $49 \mathrm{HW}$ days, only 1 belongs to the "W2 wind direction class, and none to the "SW", "S", "E" or "NW" groups (see Figure 2). Noticeably, prevailing northern winds account for the majority of HW days: $17 \mathrm{HW}$ cases are classified as " $\mathrm{N}$ " wind days, and $20 \mathrm{HW}$ cases as " $\mathrm{N}$ var" wind days; together, both groups account for $76 \%$ of HW days. There are also $11 \mathrm{HW}$ days classified as having variable wind, which agrees with the fact that this class also has an important northern wind frequency (see Figure 3).

Despite the great variety of JC weather types present in most local wind direction classes, there is some level of agreement to highlight. Firstly, the "Varying" wind days group is the only one that displays all JC weather types, which agrees with the inconstancy of the near-surface wind direction. Secondly, and more importantly, "N" (and "N var") days include a variety of synoptic conditions, and these are different between the HW and non-HW groups; while the former group includes days with Atlantic influence (i.e., $\mathrm{NW}_{\mathrm{JC}}$ and $\mathrm{W}_{\mathrm{JC}}$ cases), these synoptic conditions are absent during $\mathrm{HW}$ events, and the continental synoptic flows become more frequent $\left(\mathrm{E}_{\mathrm{JC}}\right.$ and $\left.\mathrm{NE}_{\mathrm{JC}}\right)$. In addition, out of 198 days with $\mathrm{E}_{\mathrm{JC}}$ or $\mathrm{NE}_{\mathrm{JC}}$ flows (140 in the non-HW group), $80 \%$ of cases fall within the " $\mathrm{N}$ " or " $\mathrm{N}$ var" local wind direction classes. These findings agree with previous studies that have shown that the greater air temperatures in the Iberian Peninsula [49] are mostly found under the synoptic influence of continental flows. A previous study on the regional climate of the Lisbon metropolitan area has shown that northern wind is often associated with clear skies, greater diurnal temperatures, greater thermal gradient between the coast and the inland areas, and a consistent daily rhythm of sea/land breezes, typical of coastal settings [4].

To assess the statistical significance of the UTS differences between the wind directionbased groups, hourly values were subject to pair-wise t-test, with significance adjustment per the Bonferroni method [50]. The results show that the wind direction-based classification scheme leads to significantly different types of UTS daily cycles, with contrasting intensities during at least 12 hours of the day (at the 5\% significance level) (see Figure S1, in Supplementary Materials). As expected, the most significant results (i.e., $p$-value $<0.0001$ ) correspond to the hours when the UTS reaches its maximum and minimum values, i.e., during the diurnal peak of the UCI, and the late afternoon peak of UHI intensities (from 7 to 9 p.m.). The significance is greater between " $\mathrm{N}$ " days and the remaining "Varying", "W", "SW" and "S" classes. On the other hand, differences between " $\mathrm{N}$ " and "N var" are not significant in any of the hours of the day, indicating that the additional variability in the "N var" class is not meaningful to the UTS variation. Similarly, the early hours of the day (from 6 to 10 a.m.) have either non or less significant results, which is expected since they correspond to a transition period from positive to negative UTS intensities (i.e., UHI to UCI transition), irrespective of the wind direction-based class. These results indicate that the wind direction-based classification is significantly meaningful for the interpretation of the UTS daily cycle differences in summer, particularly in terms of the diurnal UCI peak, and the late afternoon and nocturnal positive UHI stages.

\subsection{Variability of the Urban Thermal Signal (UTS) Daily Cycle, as a Function of the Prevailing Wind Direction Subsection}

In the previous section, the " $\mathrm{N}$ " and " $\mathrm{N}$ var" near-surface wind conditions at the airport were shown to be related not only to overall greater regional/background air temperatures (including HW events), but mostly with the existence of significantly different 
UTS daily cycles, at the city center, characterized by a series of hourly changes throughout the day. These include a diurnal peak of the UCI effect, a late afternoon peak of UHI intensity, and a nocturnally stable UHI anomaly. This finding is particularly important, given that the UHI potential impacts are dependent upon the overall background air temperature to which their intensity is added. Given the non-significant differences found between the " $\mathrm{N}$ " and "N var" samples, both groups are merged in this section. Here, their UTS daily cycle is compared across Lisbon's several urban air temperature (Tu) sites, during HW and non-HW days.

Figure 4 shows the daily curve of the median near-surface air temperature at Lisbon Airport and each urban site. The overlapping wind speed curve (dashed line) depicts the median values that are registered at the airport meteorological station, thus representing the wind regional conditions in Lisbon's surroundings. HW events are approximately $10{ }^{\circ} \mathrm{C}$ warmer than typical summer conditions, and the daily maximum temperature occurs soon after the solar noon at the airport meteorological station. More importantly, these plots show that, in urban sites, there is a temporal delay in terms of the urban air temperature daily maximum. This is especially true in locations characterized by greater urban density, such as RES, SAL, PNA or BEL, where a two-hour lag can be detected (see the horizontal distance between the maximum Tu50p and Tr50p vertical lines, in Figure 4). It should also be noted that, during non-HW conditions, PNA and RES are the only locations whereat the maximum daily Tu50p slightly surpasses that of the airport. That is not the case regarding the HW days' median curves. Interestingly, these same urban sites reach their peak temperatures when the regional rural wind speed is steadily increasing, suggesting that, in both sites, the positive UTS intensity results from both the built-up and topographical sheltering effects to the upwind flows. In fact, most of the city center is in a downwind location, compared to the airport, which is much more exposed to the regional northern winds.

The schematic representation of Lisbon's daily UTS cycle is shown in Figure 5, where a diagram depicts Lisbon's summer UTS daily stages, together with the hourly UTS intensities and the corresponding rate of change in $\triangle \mathrm{UTS}$ curves. Table 5 describes the criteria used to identify each UTS stage mentioned in Figure 5.

The following figures also show the same temporal patterns in the UTS intensities: firstly, Figure 6 shows the hourly statistical distribution of the UTS intensity, highlighting the 10th, 50th and 90th percentile curves (UTS10p, UTS50p and UTS90p, respectively), during HW and non-HW days; secondly, Figure 7 depicts the heatmaps of the monthly changes in the previously mentioned UTS percentile levels.

The results show that there is a consistent pattern in the UTS daily cycle, whereby typical stages can be identified, on every site, irrespective of the percentile curve, or month, and are not common to HW and non-HW days. These can be identified by the signal of the UTS intensity, and by the rate of change of this intensity, as determined by the criteria presented in Table 5. These stages can be described as follows: (i) Stage 1, a nocturnal stable UHI that lasts from the late evening hours until dawn, when there are very slow rates of change in the UTS intensity (i.e., near zero $\triangle$ UTS) and a UHI exists in the most developed urban sites (e.g., RES, SAL, PNA and BEL); (ii) Stage 2, a morning transition to UCI, during which the $\triangle \mathrm{UTS}$ values decrease by more than $-0.2^{\circ} \mathrm{C} / \mathrm{h}$; (iii) Stage 3 , a diurnal minimum UTS that mostly translates into the peak values of a UCI effect, prevalent in all locations; (iv) Stage 4, an afternoon transition period during which $\Delta$ UTS values increase by more than $0.2^{\circ} \mathrm{C} / \mathrm{h}$; (v) Stage 5 , a late afternoon maximum UTS value that translates into the peak UHI moment of the day in the most developed urban sites (i.e., RES, SAL, BEL, and PNA), irrespective of the percentile curve, month, or existence of HW conditions; and finally (vi) Stage 6, a transition period when the maximum UTS intensity stabilizes into Stage 1. 
Air temperature (Ta) and wind speed (Ws) daily cycle, Summer (JJAS 2005-2014)

(' $\mathrm{N}$ ' and ' $\mathrm{N}$ var' wind direction)
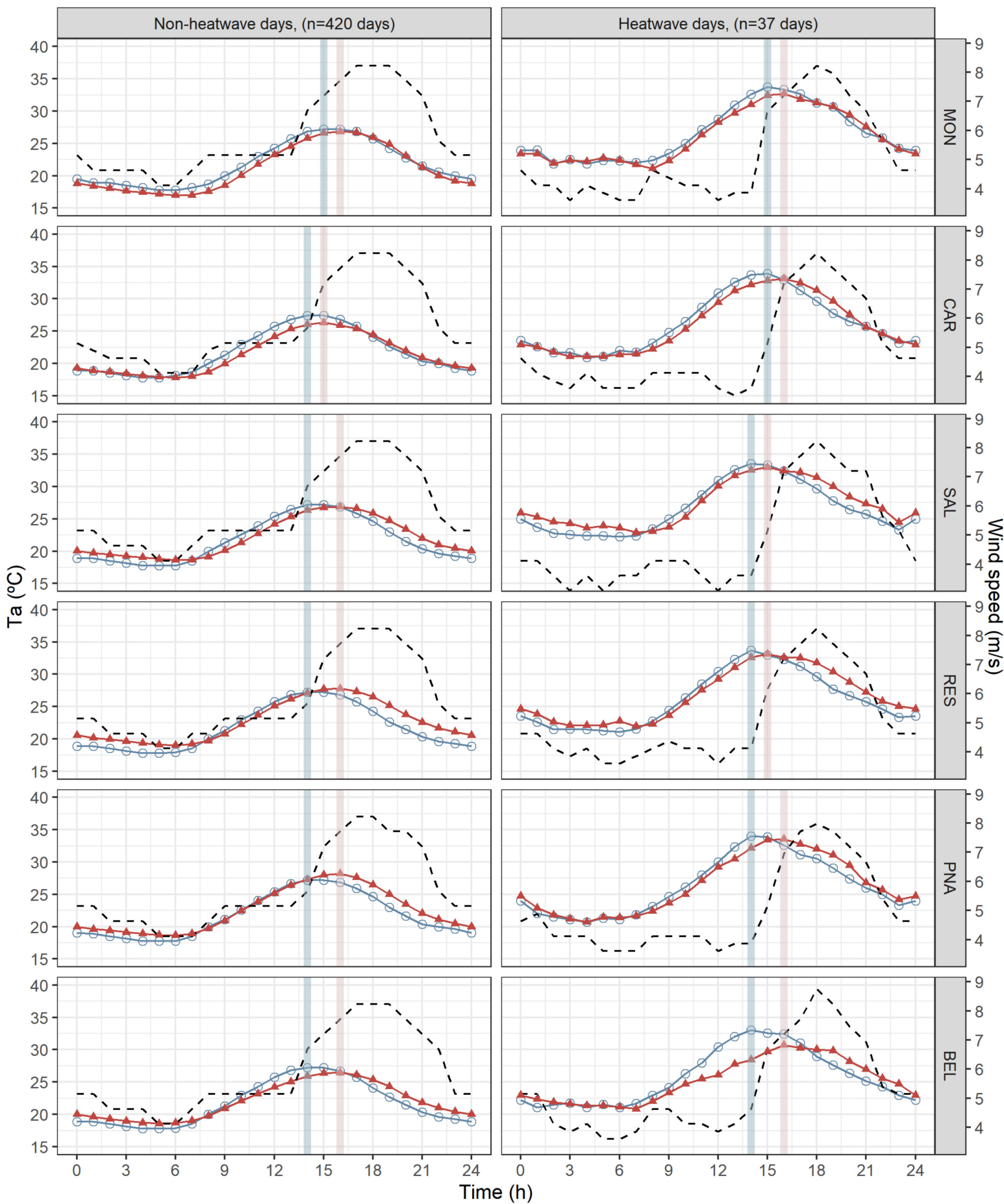

— Lisbon Airport Ta (Tr): Median (Tr50p)
— IGOT's urban sites Ta (Tu): Median (Tu50p)
_- Lisbon Airport regional wind speed (Ws50p)

Lisbon Airport daily peak (max. Tr50p)

IGOT's urban sites daily peak (max. Tu50p)

Figure 4. Hourly profiles of air temperatures and wind speed, during heatwave (HW) and non-heatwave (non-HW) conditions: median air temperature at Lisbon Airport, $\operatorname{Tr}(\operatorname{Tr} 50 \mathrm{p})$, median urban air temperatures, $\mathrm{Tu}(\mathrm{Tu} 50 \mathrm{p})$, and median wind speed (Ws50p) at Lisbon Airport. 


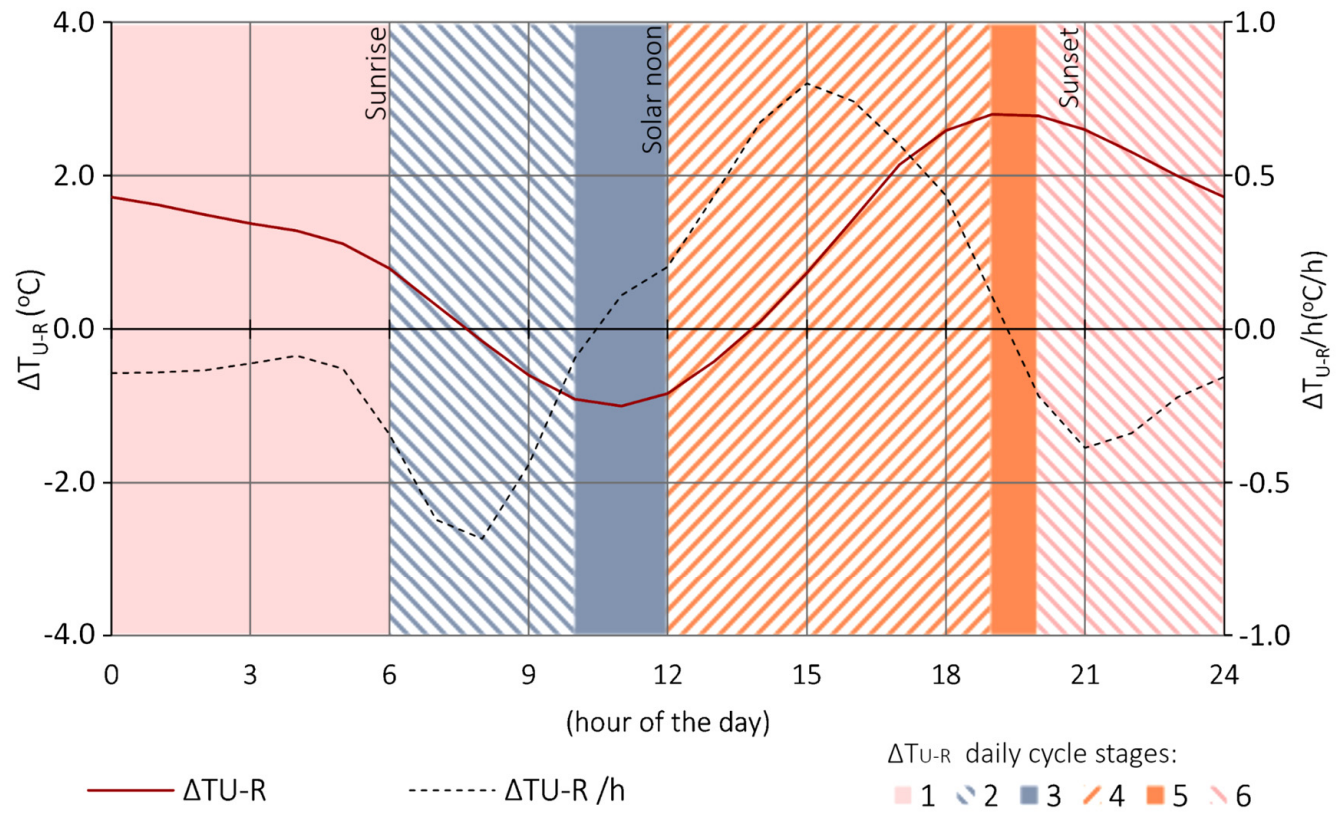

Figure 5. Diagram of the UTS daily cycle stages: the solid and dashed lines show the hourly intensities of the UTS and $\triangle$ UTS in Lisbon city center, respectively. These correspond to a smoothed version of the RES site median values (3 $\mathrm{h}$ moving average).

Table 5. Classification criteria of the UTS daily cycle stages in Lisbon.

\begin{tabular}{|c|c|c|c|c|}
\hline & JTS Daily Cycle Stages & Period of the Day & UTS Signal & $\Delta$ UTS Signal \\
\hline 1 & Nocturnal stable UHI & Night & Positive & Near zero \\
\hline 2 & Morning transition to UCI & $\begin{array}{c}\text { Early } \\
\text { morning }\end{array}$ & $\begin{array}{c}\text { Positive to } \\
\text { negative } \\
\text { transition }\end{array}$ & Negative \\
\hline 3 & Diurnal Peak UCI & Day & Negative & $\begin{array}{c}\text { Negative to } \\
\text { positive } \\
\text { transition }\end{array}$ \\
\hline 4 & Afternoon transition to UHI & Afternoon & $\begin{array}{c}\text { Negative to } \\
\text { positive } \\
\text { transition }\end{array}$ & Positive \\
\hline 5 & Late Afternoon peak UHI & $\begin{array}{c}\text { Late } \\
\text { afternoon }\end{array}$ & Positive & $\begin{array}{l}\text { Positive to } \\
\text { negative } \\
\text { transition }\end{array}$ \\
\hline 6 & Evening stabilizing UHI & Evening & Positive & Negative \\
\hline
\end{tabular}

While these UTS stages are found in every location, there are differences between sites concerning the intensity and the time of the day when the peak values occur (see Figures 6 and 7). During non-HW conditions, the Stage 5 median peak UHI intensity in Lisbon's most built-up areas (RES, SAL, and PNA) varies between 1.6 and $2.5^{\circ} \mathrm{C}$ (UTS50p of SAL and RES sites, respectively). This intensity sometimes surpasses $4.0^{\circ} \mathrm{C}$ (UTS90p). In addition, $50 \%$ of the days have a nocturnal UHI intensity greater than $1.3^{\circ} \mathrm{C}$ (RES UTS50p is detected; the equivalent upper bound (90th percentile, UTS90p) is $2.3^{\circ} \mathrm{C}$ (RES UTS90p)). The median UHI intensities during the peak and nocturnal stages show a difference of less than $0.5^{\circ} \mathrm{C}$ when comparing between $\mathrm{HW}$ and non-HW days, in every site; nonetheless, many sites show that $\mathrm{HW}$ days have up to $0.5^{\circ} \mathrm{C}$ lower maximums in the 90th percentile curves (see Figures 6 and 7, e.g., PNA and SAL). 
Urban Thermal Signal (UTS) daily cycle, Summer (JJAS, 2005-2014)

('N' and 'N var' wind direction)

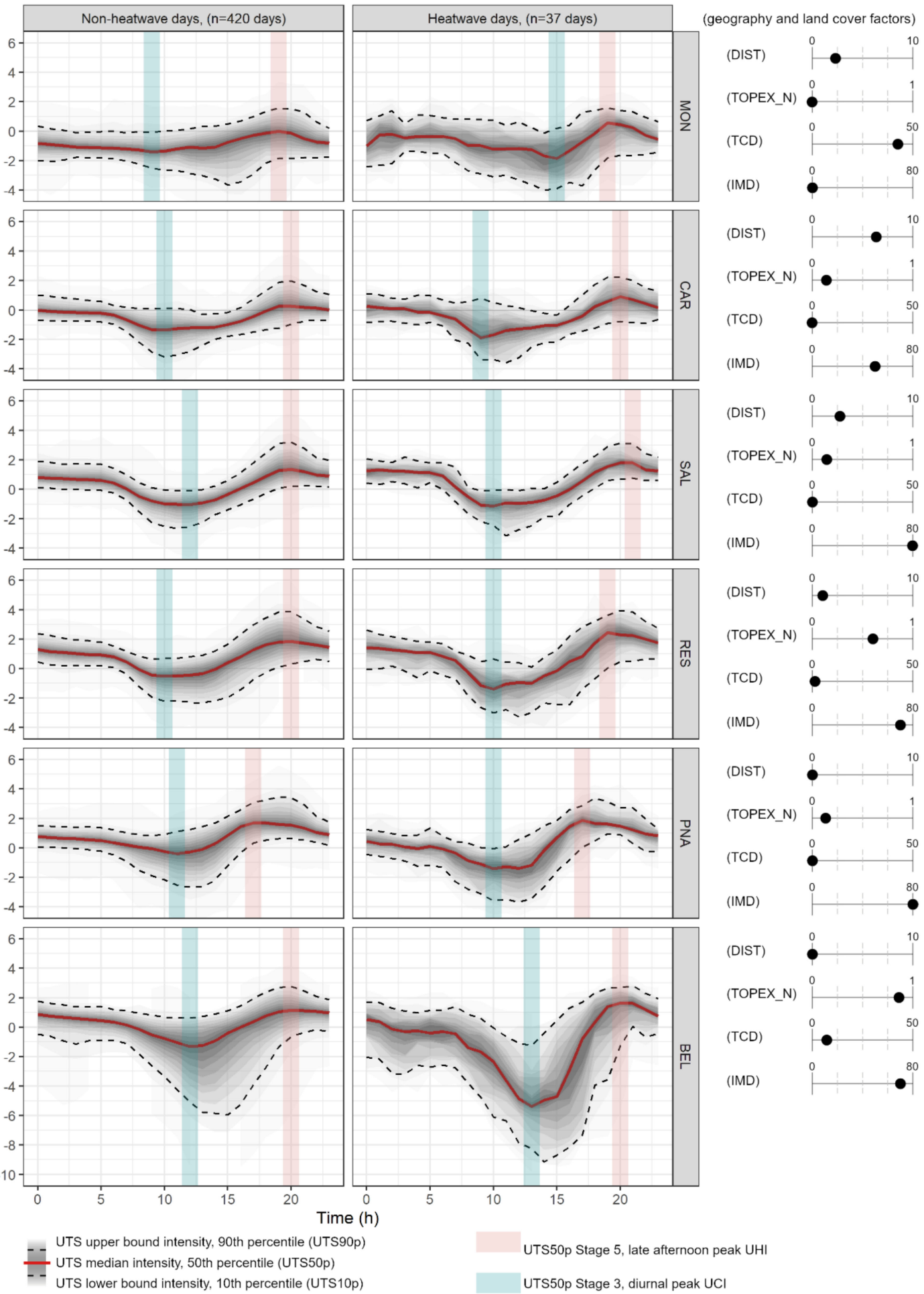

Figure 6. The statistical distribution of the hourly urban thermal signal (UTS) intensities, per site, during heatwave (HW) and non-heatwave (non-HW) conditions: solid lines represent the median hourly UTS intensities (UTS50p), dashed lines represent the 10th and 90th percentile curves (UTS10p and UTS90p, respectively), and the grey gradient depicts the statistical spread by 0.5 probability intervals. Vertical shaded areas correspond to the UTS50p daily minimum (blue, or dark grey) and maximum (red, or light grey). On the righthand side, schematic plots illustrate the characteristics of each site, which were mentioned in Table 1 and Figure 1. 
Urban Thermal Signal (UTS) daily cycle, per month, Summer (JJAS, 2005-2014) (' $\mathrm{N}$ ' and ' $\mathrm{N}$ var' wind direction)

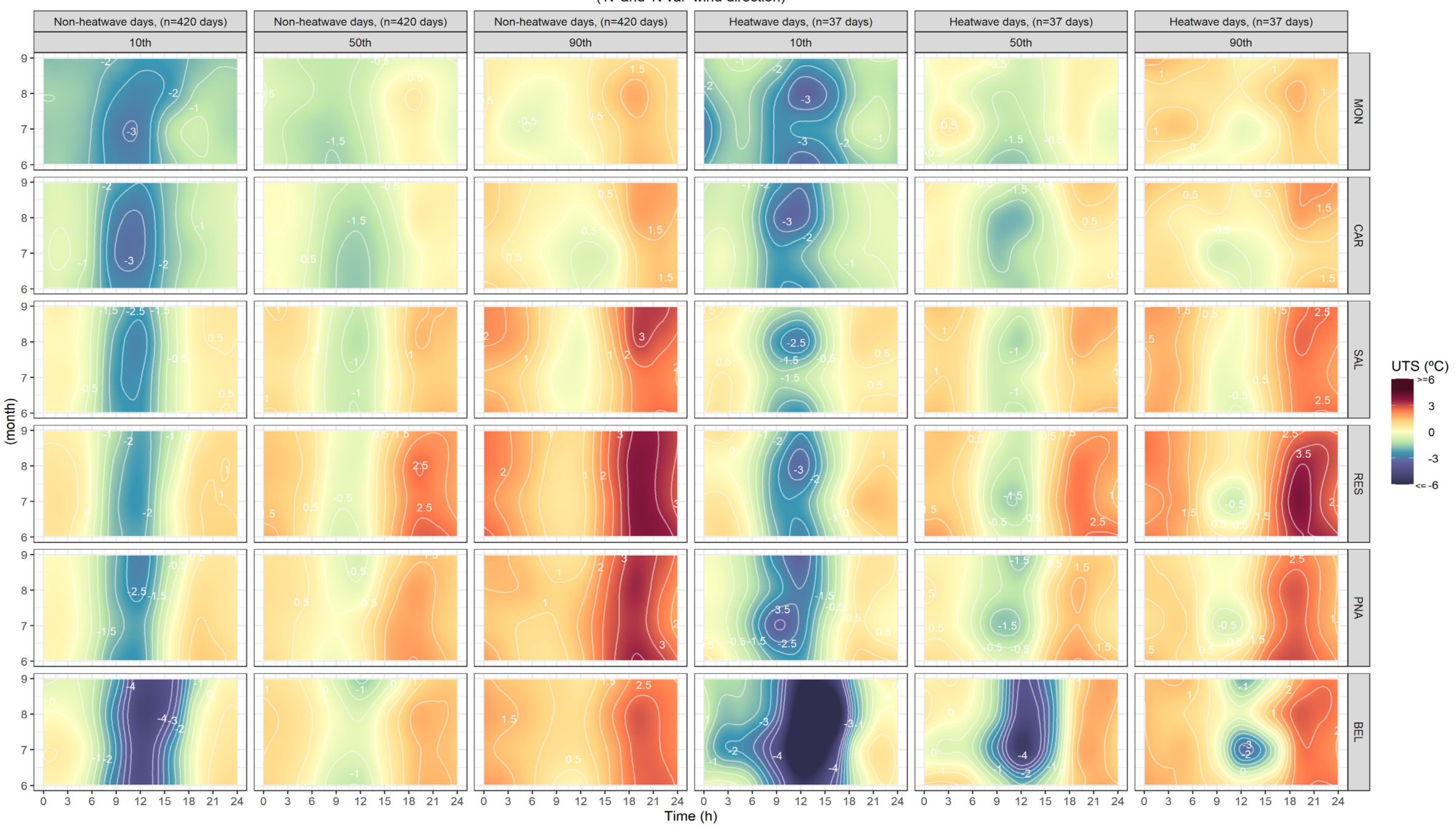

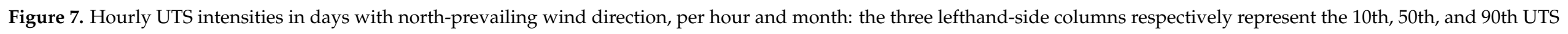
percentiles in non-heatwave days, and the three right-hand-side columns represent the 10th, 50th, and 90th UTS percentiles in heatwave days. 
The period of the day when the peak UHI occurs is different across sites. In PNA, it happens 2 h sooner (at about 5 p.m.); in RES and SAL (central area of the city), this occurs later, at about 7 to 8 p.m. (the same in BEL and CAR, although their UHI peak intensities are lower). The existence of $\mathrm{HW}$ conditions does not cause a relevant difference in these timings. Interestingly, while the CAR and MON sites are characterized by the absence of a consistent UHI effect, they both reveal a minor suggestion of the UTS cycle found in the other urban locations, particularly in CAR, which is also a built-up site (even though less dense, and more exposed to northern winds). Finally, we should note a distinct feature in the UTS found in the BEL location: being located in the westernmost riverside part of the city, exposed to both the estuary and coastal breezes, this site reveals the greatest inter-percentile distances, especially during the day. Although there are currently no data available to disclose the influence of these riverside/coastal breezes on the local thermal conditions, this finding suggests that they might be a determinant culprit for this greater statistical spread.

To understand if there is a statistically significant difference between the HW and nonHW days, additional t-testing was conducted between the daily UHI and UCI intensities, during stages 1, 3 and 5 of the UTS per site. At stages 3 and 5, the peak intensities of the UCI and UHI, respectively, were statistically sampled as daily minimum and maximum UTS intensities, during the 3-hour period when they usually occur (i.e., from 11 a.m. until 2 p.m., and from 5 p.m. until 8 p.m., respectively), for every site. Stage 1, corresponding to the stable nocturnal UHI period, was sampled as the daily median UTS intensity, from 11 p.m. until 6 a.m., on every site, as well. The daily time-series were then subject to t-testing, with the null hypothesis being that the HW and non-HW daily time-series had similar distributions, per site. The results are shown in Table S2, in Supplementary Materials. The results indicate that there are mostly non-significant differences between the HW and nonHW samples, during the times of the day when a UHI effect exists. This is common to every site, during the peak late afternoon UHI (stage 5), and to all but OUR and PNA during the nocturnal stable UHI period. On the other hand, four significant results occured in the diurnal period, particularly in the hours during which the UTS reaches its minimum, at SAL, RES, PNA and BEL. These significant differences result from an overall intensification of the midday UCI effect (i.e., lower UTS intensities) during HW events, a difference that varies between $0.5^{\circ} \mathrm{C}$ (e.g., in SAL or RES) and more than $4.0^{\circ} \mathrm{C}$ (e.g., in BEL).

Finally, the "N" and "N var" groups were shown to have a significant percentage of synoptic conditions typically related with warmer weather, i.e., $\mathrm{A}_{\mathrm{JC}}, \mathrm{E}_{\mathrm{JC}}$ and $\mathrm{NE}_{\mathrm{JC}}$ types, but this also includes several days of $\mathrm{N}_{\mathrm{JC}}, \mathrm{W}_{\mathrm{JC}}$ or $\mathrm{U}_{\mathrm{JC}}$ types. To highlight synoptic-related differences, Table 6 summarizes the daily mean air temperature, thermal amplitude and UTS intensities (stage 1, nocturnal stable UHI, and stage 5, late afternoon peak UHI) that can be found per JC weather type, within the "N" / "N var" groups of days. In addition, Figure 8 shows the boxplots of the statistical distribution of UTS intensities at the city center (RES site) during the main three UTS stages (1,3 and 5); these plots highlight the differences between the most frequent JC weather types related with HW conditions, within the "N" /"N var" group of days. As expected, anticyclonic $\left(\mathrm{A}_{\mathrm{JC}}\right)$ and continental advection $\left(\mathrm{E}_{\mathrm{JC}}\right.$ and $\left.\mathrm{NE}_{\mathrm{JC}}\right)$ conditions show greater daily mean temperatures and thermal amplitudes, which reach $11^{\circ} \mathrm{C}$ during HW events. The nocturnal and late afternoon UHI intensities are the smallest when $\mathrm{E}_{\mathrm{JC}}$ occurs ( 0.6 to 0.8 and 1.4 to 1.5 , during stages 1 and 5 of the UTS daily cycle, respectively), and the UCI stage has the smallest negative value, as well; however, its frequency $(4 \%)$ is quite low, compared to other synoptic types, and the statistical spread increases in the HW days group. The single case of statistical significant UHI increase, during $\mathrm{HW}$ conditions, corresponds to the $\mathrm{U}_{\mathrm{JC}}$ type, but only during the late afternoon stage (Stage 5). Contrariwise, the other JC weather types that are most frequent during HW $\left(\mathrm{A}_{\mathrm{JC}}\right.$ and $\left.\mathrm{NE}_{\mathrm{JC}}\right)$ have non-statistically significant differences between their nocturnal and late afternoon UHI intensities, nor between HW and non-HW days (per t-test). 
Table 6. Characterization of the daily mean air temperature, thermal amplitude and UTS intensity of " $N$ " and "N var" days, per Jenkinson-Collison (JC) types, summer (JJAS, 2005-2014).

\begin{tabular}{|c|c|c|c|c|c|c|c|c|c|c|}
\hline \multirow{3}{*}{ JC Type $^{1}$} & \multirow{2}{*}{\multicolumn{2}{|c|}{ Percentage Days ${ }^{1}$}} & \multirow{2}{*}{\multicolumn{2}{|c|}{$\begin{array}{l}\text { Daily Mean Air } \\
\text { Temperature }\left({ }^{\circ} \mathrm{C}\right)\end{array}$}} & \multirow{2}{*}{\multicolumn{2}{|c|}{$\begin{array}{c}\text { Daily Mean Thermal } \\
\text { Amplitude }\left({ }^{\circ} \mathrm{C}\right)\end{array}$}} & \multicolumn{4}{|c|}{ Daily Mean UTS Intensity } \\
\hline & & & & & & & \multicolumn{2}{|c|}{$\begin{array}{c}\text { Stage } 1, \text { Stable UHI }{ }^{2} \\
\left({ }^{\circ} \mathrm{C}\right)\end{array}$} & \multicolumn{2}{|c|}{$\begin{array}{c}\text { Stage 5, Peak UHI }{ }^{2} \\
\left({ }^{\circ} \mathrm{C}\right)\end{array}$} \\
\hline & non-HW & $H W$ & non-HW & $H W$ & non-HW & $H W$ & non-HW & $H W$ & non-HW & $H W$ \\
\hline $\mathrm{A}_{\mathrm{JC}}$ & 20 & 10 & 22.7 & 24.2 & 10.0 & 11.1 & 1.4 & 1.4 & 3.2 & 2.4 \\
\hline $\mathrm{C}_{\mathrm{JC}}$ & 3 & 0 & 22.7 & n.a. & 8.4 & n.a. & 1.5 & n.a. & 2.4 & n.a. \\
\hline $\mathrm{N}_{\mathrm{JC}}$ & 11 & 0 & 20.9 & n.a. & 6.9 & n.a. & 1.1 & n.a. & 2.7 & n.a. \\
\hline $\mathrm{NE}_{\mathrm{JC}}$ & 34 & 43 & 23.1 & 24.9 & 9.3 & 9.2 & 1.1 & 1.4 & 2.6 & 3.0 \\
\hline $\mathrm{E}_{\mathrm{JC}}$ & 4 & 13 & 25.3 & 28.2 & 9.5 & 7.7 & 0.8 & 0.6 & 1.4 & 1.5 \\
\hline $\mathrm{w}_{\mathrm{JC}}$ & 1 & 0 & 23.5 & n.a. & 9.3 & n.a. & 2.6 & n.a. & 2.6 & n.a. \\
\hline $\mathrm{NW}_{\mathrm{JC}}$ & 2 & 0 & 22.1 & n.a. & 7.1 & n.a. & 1.1 & n.a. & 2.3 & n.a. \\
\hline $\mathrm{U}_{\mathrm{JC}}$ & 16 & 33 & 23.0 & 25.8 & 8.9 & 7.6 & 1.3 & 1.6 & 2.7 & 3.6 \\
\hline
\end{tabular}

1 only major JC weather types were considered, thus 68 days (out of 420 ) with hybrid synoptic conditions were excluded from this analysis; 2 at the city center, RES site.

\section{Boxplots of the Urban Thermal Signal (UTS), per most frequent Jenkinson-Collison (JC) weather types during heatwaves} Intensities in the RES site, during near-surface ' $\mathrm{N}$ '/ $\mathrm{N}$ var' wind conditions
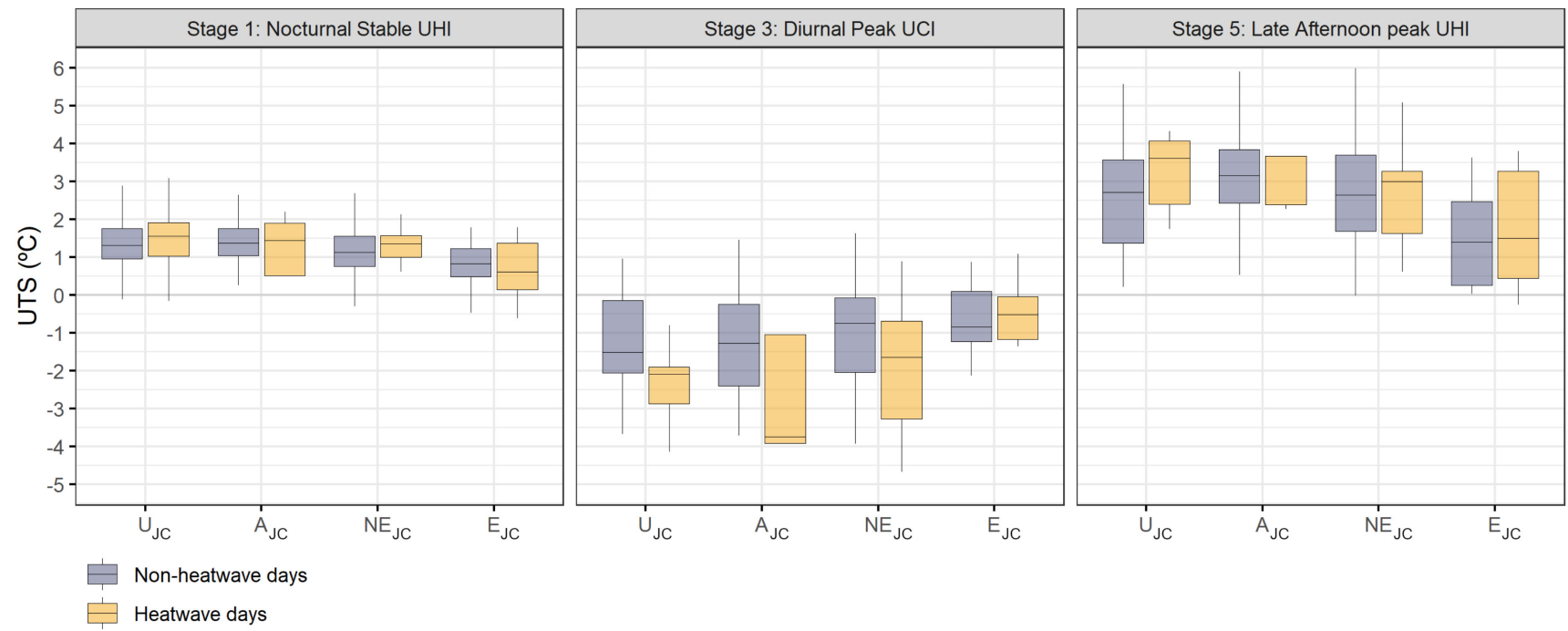

Figure 8. Urban thermal signal (UTS) per most frequent Jenkinson-Collison (JC) weather types during HW events; intensities in the RESs site (city center) during "N"/"N var" near-surface wind conditions.

\section{Discussion}

The importance of the UHI effect is often supported by the notion of a positive relationship between its intensity and the overall air temperature, during HW events [13,29]. Several studies have addressed this issue in several climatic contexts [13-15,17,18], describing and quantifying the urban fabric's positive thermal response to extreme temperatures. However, results from this study clarify how this argument needs to be evaluated further, in the case of Lisbon.

In fact, most case studies from the literature, concerning the daily cycle of the urban to rural temperature difference, describe a different UTS daily cycle, having (i) a diurnal UCI period, after solar noon; (ii) a nocturnal UHI period, from late night until morning; and (iii) two fast-changing transition periods, intermediate between the previously mentioned ones. Often, the schematic representation of the UTS temporal variation is a depiction of this mirrored silhouette [34,35], a daily profile that is also supported in a more recent worldwide study using harmonic functions to explore the asymmetry of the urban daily air temperature cycle [36]. Moreover, recent case study examples of the temporal variation in the UHI magnitude describe similar harmonic curves; examples include cities across 
several climatic contexts and geographical settings, such as Vancouver, London, Edmonton, Uppsala and St. Louis [51], Chongqing [52], Oklahoma [53], or Buenos Aires [54].

However, in Lisbon, the existence of a UHI effect, and the corresponding daily cycle, is shown to depend mostly on the prevailing wind direction. Only northern wind conditions show the existence of a consistently positive UTS in the city center and most developed sites. In such cases, instead of having two "plateau" periods, the daily maximum UHI intensity occurs during the late afternoon hours of the day, and only then stabilizes in a $1.3^{\circ} \mathrm{C}$ median thermal anomaly throughout the night. Thus, Lisbon's north-related UTS daily cycle is characterized instead by six different stages, as mentioned in Section 3.2, which is relevant, given the facts that (i) in Lisbon, northern wind days are predominant during the summer (457 days out of 767 analyzed), and that (ii) these conditions are shown to be associated with greater near-surface air temperatures, including the fact that 37 out of $49 \mathrm{HW}$ days have predominant north wind. Previous studies have pointed out how local weather conditions in Lisbon can by typified, highlighting the relation between daily temperature, wind speed and humidity, with synoptic conditions $[33,55]$. Furthermore, even though extreme temperatures in Portugal are related with high-altitude eastern/continental air mass movements [49], i.e., those corresponding to $\mathrm{NE}_{\mathrm{JC}}, \mathrm{E}_{\mathrm{JC}}$ or stable $\mathrm{A}_{\mathrm{JC}}$ synoptic types, at the near-surface level, northern winds prevail, which is typically called "nortada".

The current study highlights how these HW-inducing synoptic conditions (typically days with clear skies, greater daily maximum air temperatures, greater thermal amplitudes, and a significant thermal gradient from the coast to the inland regions) can be associated with Lisbon's near-surface regional northward wind regimes. Given the fact that the city development is mostly located in the southern and lower areas of the sloped territory, i.e., lee-ward of the prevailing winds, this study reinforces previous suggestions that the local UTS intensity, and the corresponding daily UHI intensity, are not purely a UHI effect per se, in that their intensity results from the added contributions of both the built-up thermal storage and the topographical shelter [55]. While the UTS daily cycle is similar between " $\mathrm{N}$ " and " $\mathrm{N}$ var" days, $\mathrm{HW}$ events and warmer summer days require the existence of $\mathrm{NE}_{\mathrm{JC}}$, $\mathrm{E}_{\mathrm{JC}}, \mathrm{U}_{\mathrm{JC}}$ and $\mathrm{A}_{\mathrm{JC}}$ synoptic conditions, thus the coexistence of both conditions can be used to establish the possibility of excess heat exposure, within the city.

On the other hand, extreme air temperatures do not make a significant contribution to increasing UHI intensities, either during the late afternoon peak (stage 5) or during the night (stage 1). The only exception is during the late afternoon, when synoptic conditions correspond to the $\mathrm{U}_{\mathrm{JC}}$ weather type. Contrariwise, when continental flows are easternly $\left(\mathrm{E}_{\mathrm{JC}}\right)$, the UTS values decrease. These results suggest that, in Lisbon, the urban thermal difference is as much a function of the thermal storage in built-up areas as it is a consequence of the natural and built-up sheltering effect of the topography to northern flows. As such, HW days may have peak UHI intensities up to $4.4^{\circ} \mathrm{C}$ in the upper level (UTS90p curves), or these may be as low as $0.5^{\circ} \mathrm{C}$ (UTS10p curves), which is equivalent to non-HW days (see Table S1, in Supplementary Materials, and Figures 6 and 7).

Although a positive interaction between UHIs and heat waves has been demonstrated in several regions, different results were also observed in cities under different local background climates. Previous examples of positive interactions between HW and the UHI effect have been found in Atlanta [18], Athens [13], Beijing, Guangzhou and Shanghai [56], and Paris [29]. In the first study, meteorological data from three stations (one urban, one hybrid and one rural) were used, covering the 1984 to 2007 period, and a $1.0^{\circ} \mathrm{C} \mathrm{UHI}$ intensity increase was detected between HW and non-HW days. In the latter study, only observations from two stations (one urban and one rural), during the 2003 summer period, were considered. In both the Atlanta and Paris studies, wind direction was not included. A more meaningful comparison can be made with Ref. [13], which is also a southern European coastal city, within the Mediterranean region, due to the inclusion of a wind direction-based analysis. By comparison, Lisbon's results are contrary to those found in Greece [13], where the authors have analyzed data from five stations across the Greater Athens Area (GAA), to show how the local UHI effect significantly increases with temperature, particularly 
during HW conditions, and during the day. In addition, contrasting with Lisbon's case, the GAA's UHI usually weakens under north and northeastern wind conditions, irrespective of the temperature level, and conditions favorable to sea breeze development are shown to induce pronounced UHI intensification. However, in Ref. [13], the authors only considered a single urban site, compared to four coastal sites. In addition, the time period covered in Ref. [13] was smaller (July-August 2012), thus accounting for only five HW events, whereas in this study, 12 years of data were included. More recently, Ref. [57] analyzed 5 years of mesoscale atmospheric data (from 2014 to 2019), acquired by the MUSTARDijon network, which includes 60 sensors. Results from the Dijon case study agree with this study findings, since no significant relation was detected between HW events and the UHI intensity [57]. In addition, the authors point out how the UHI intensity decreases after the onset of HW conditions, suggesting that the urban air temperature remains stationary, while the rural air temperature changes the most due to the evapotranspiration decrease.

The implications of these findings are twofold. Locally, these conclusions are relevant to supporting climate change adaptation strategies, as the daily mean and daily peak UHI intensities are found to be highly dependent on the regional near-surface wind conditions, but are also influenced by the major synoptic-scale flows; thus, any modeling attempt of the urban excess heat exposure levels has to consider how the UTS daily cycle varies, per wind direction, and how its intensity results from the added contribution of both the urban development and the natural shelter conditions to the prevailing regional flows. In Lisbon, "adapting to the worst-case scenario" requires the understanding that greater UHI intensities are found with near-surface northern winds, which occur in the great majority of days, irrespective of being HW or non-HW circumstances. These data show no evidence that Lisbon's UHI intensity does increase with a higher temperature. This partially disagrees with several previous studies $[13,18,29]$ in other cities that have found a UHI increase during HW conditions. Thus, it reinforces the argument that caution should be taken when generalizing their findings to other locations, as mentioned by some authors [16]. Out of the several synoptic conditions that lead to HW events, only $\mathrm{E}_{\mathrm{JC}}$ flows seem to attenuate the UHI intensity, but they are more scarce. Conversely, UHI intensities surpassing $3.0^{\circ} \mathrm{C}$ can be found at the city center (as well as other LCZ 2 sites, such as PNA and SAL), in the remaining $\mathrm{HW}$ cases $\left(\mathrm{NE}_{\mathrm{JC}}\right.$ and $\left.\mathrm{A}_{\mathrm{JC}}\right)$. This is a temperature addition that might be relevant to the local thermal discomfort levels, given the fact that HW late afternoon air temperatures are frequently greater than $30^{\circ} \mathrm{C}$.

Even though the translation of these results into human bioclimatic indices is not the subject of this study, it should be noted that, in Lisbon, the synoptic conditions that lead to near surface extreme temperatures are mostly related with continental air masses, and corresponding lower $\mathrm{RH}$ values ( $\mathrm{NE}_{\mathrm{J}}$ and $\mathrm{E}_{\mathrm{J}}$ synoptic weather types) [33,55]. Accordingly, despite the overall importance of RH to human thermal stress [58], recent climate studies in Lisbon did not show significant changes in bioclimatic comfort that were attributable to higher values of this variable [19].

To the urban climate community, these conclusions are also meaningful, as this casespecific UTS daily cycle illustrates the importance of the local geographic factors in accurately inferring the UHI spatio-temporal patterns, in riverside/coastal cities with intricate topographies, as mentioned in the Geographical Controls chapter of Ref. [12]. This city's example illustrates how much of the methodologies explored by many recent studies, focusing mostly on associating built-up parameters (such as density, building height, sky-view factor, LCZ classes, among others indices) with the urban thermal anomaly, are insufficient to accurately represent case study regions where the complicated geographical context plays a determinant role in the thermal signal of the city. Here, the wind direction dependence of the UHI intensity greatly suggests the relevance of how much local wind flows can penetrate the urban fabric. Strategies that consider both the buildings' geometry and the natural geographical setting have been developed before, with examples including the urban climate mapping scheme that is based on the identification of homogenous climate response areas $[8,59,60]$. Those lessons should be integrated into urban climate 
modeling, such as the models based on the LCZ scheme, to fully provide insights into the local UTS, especially in complex geographical settings, as is Lisbon's case (an example that is representative of many other southern European cities).

Such considerations also have implications when defining climate change adaptation strategies, since future UHI scenarios cannot be based solely on the temperature increase. Here, the relation between wind direction and the UHI effect shows the importance of considering additional climate variables, such as changes in regional wind patterns. According to Ref. [19], no significant wind speed changes have occurred in the Lisbon metropolitan area, thus there is generally little confidence in establishing future wind scenarios.

The limitations of this study are mostly concerned with data constraints. Some sites have incomplete time series, and the temporal discontinuities pose a challenge by diminishing the amounts of synchronous air temperature measurements available. In addition, there are no readily available datasets regarding other local wind flows, besides that of Lisbon Airport. There are existing stations measuring wind speed and direction, namely at Cais do Sodré and Matinha; however, it has been challenging to ensure access to data. This is a significant limitation, as wind breezes from the river and coast are known to have an important role locally. Future work will consider the available information to develop a UTS prediction model, to disentangle the intricate contributions of the natural and man-made landscapes to Lisbon's urban climate.

\section{Conclusions}

While the city of Lisbon is located within the hot-summer Mediterranean climatic region (Köppen Csa class) [1,2], its topography and proximity to the Atlantic coast greatly influence the daily cycle of the local UTS [4,5]. Given the urgency of adapting to a changing climate wherein HW will become more frequent, lengthy and intense [19], in this study, the summer near-surface air temperature measurements from Lisbon's mesoscale network are used to disclose the interactions between the regional background weather conditions and the thermal performance throughout the city. Given previous insights regarding local climate, wind direction frequencies are used to classify days accordingly, and compare the UTS intensity during both HW and non-HW days. T-test results between hourly samples show that the wind direction-based classification translates into groups of days with significantly contrasting UTS daily cycles (at the 95\% level). Northern wind ("N" /"N var") days prevail during the summer (457 days out of 767 days), and are shown to be associated with greater maximum air temperatures (Tx) that range from 24 to $34{ }^{\circ} \mathrm{C}$ ( $\mathrm{Tx}$ 10 th and 90th percentiles, respectively), greater thermal amplitudes (approximately $10^{\circ} \mathrm{C}$ ), and a consistent late afternoon peak of wind speed. Out of the 49 EHF-based HW, 37 are also "N" /"N var" days. As a result, the corresponding daily UTS reveals a distinct daily cycle that can be classified into stages: (i) a mid-day urban cooling island (UCI) (median UTS is approximate $-1.0^{\circ} \mathrm{C}$ ) in the city center; an urban heat island (UHI) peak intensity occurring throughout the late afternoon hours, from 2.0 to $2.5^{\circ} \mathrm{C}$ (median UTS), but occasionally surpassing the $4.0^{\circ} \mathrm{C}$ (UTS 90th percentile); and a stable nocturnal UHI of $1.3^{\circ} \mathrm{C}$ that persists until the sunrise hours. In the transition periods between these stages $(2,4$ and 6$)$, the UTS intensity absolute rate of change surpasses $0.2^{\circ} \mathrm{C}$ per hour. By contrast, western, southwestern and southern ("W", "SW" and "S") wind days are characterized by milder air temperatures, lower thermal amplitude and only very slight UTS intensity changes throughout the day. The HW days' UTS daily cycles reveal a similar daily cycle, and less than $0.5^{\circ} \mathrm{C} \mathrm{UHI}$ intensity differences, when compared to non-HW days. Given the topography of the city's setting, the southernmost locations, particularly the city center site (RES), are naturally more sheltered from northern and northwestern wind flows, and are more exposed to the penetration of southern winds and/or sea/river breezes (due to riverside proximity). This is shown by the stark UTS differences that can be found in the RES site when comparing " $\mathrm{N}$ " and " $\mathrm{S}$ " days. These results suggest that, in addition to the urban morphology or surface, there is a significant contribution of the natural topography to Lisbon's nocturnal UHI effect in the city center. This wind direction-dependency of the 
UTS response differs from other cities', where urban density alone is shown to aggravate the UHI intensity during HW events. The results suggest that to completely model Lisbon's UHI, both the built-up occupation and natural terrain conditions have a significant role to play, and one has to control for topographic exposure to accurately interpret the specific impact of built-up occupation on the local UTS. Future work will consider the available information to develop such a UTS prediction model, in an attempt to disentangle the intricate contributions of the natural and man-made landscapes to Lisbon's urban climate.

Supplementary Materials: The following are available online at https:/ / www.mdpi.com/2073-4 433/12/3/292/s1, Figure S1: Significance of the urban thermal signal (UTS) daily cycle differences between wind direction-based groups, Table S1: Significance of the urban thermal signal (UTS) differences between heatwave (HW) and non-heatwave (non-HW) days, Table S2: Significance of the Urban Thermal Signal (UTS) differences between heatwave (HW) and non-heatwave (non-HW) days: comparison between the daily UHI and UCI intensities the UTS stages 1, 3 and 5. T-test significance, with $p$-values adjusted by Bonferroni method [44]. Bold font indicates statistically significant differences found between HW and non-HW days..

Author Contributions: Conceptualization, A.O., A.L. and E.C.; methodology, A.O., A.L. and E.C.; software, A.O.; validation, A.L., E.C. and A.S.; formal analysis, A.O.; investigation, A.O.; resources, A.O. and S.N.; data curation, A.O. and E.C.; writing-original draft preparation, A.O.; writingreview and editing, A.L., E.C. and S.N.; visualization, A.O.; supervision, A.L., A.S. and S.N. All authors have read and agreed to the published version of the manuscript.

Funding: This research was funded by national funds through FCT—Fundação para a Ciência e a Tecnologia [Ph.D. Grant NO. PD/BD/52304/2013]. This research was funded by FCT-Fundação para a Ciência e Tecnologia, I.P. [CEG projects numbers: UIDB/00295/2020 and UIDP/00295/2020].

Institutional Review Board Statement: Not applicable.

Informed Consent Statement: Not applicable.

Conflicts of Interest: The authors declare no conflict of interest.

\section{References}

1. Köppen, W. Grundriss der Klimakunde; Walter de Gruyter: Berlin, Germany, 1931.

2. Peel, M.C.; Finlayson, B.L.; McMahon, T.A. Updated world map of the Köppen-Geiger climate classification. Hydrol. Earth Syst. Sci. 2007, 11, 1633-1644. [CrossRef]

3. Alcoforado, M.J.; Andrade, H.; Lopes, A.; Vasconcelos, J.; Vieira, R. Observational studies on summer winds in Lisbon (Portugal) and their influence on daytime regional and urban thermal patterns. Merhavim 2006, 6, 90-112.

4. Alcoforado, M.J. O Clima da Região de Lisboa. Contrastes e Ritmos térmicos. In Memórias do Centro de Estudos Geográficos; Centro de Estudos Geográficos: Lisbon, Portugal, 1992; ISBN 972-636-094-3. (In Portuguese)

5. Alcoforado, M.J.; Lopes, A.; Alves, E.D.L.; Canário, P. Lisbon heat island statistical study (2004-2012). Finisterra 2015, 49. [CrossRef]

6. Alcoforado, M.J. Assessing and Modeling the Urban Climate in Lisbon. In Geographical Information and Climatology; ISTE-Wiley: London, UK, 2013; ISBN 9781848211858.

7. Lopes, A.; Alves, E.D.L.; Alcoforado, M.J.; Machete, R. Lisbon Urban Heat Island Updated: New Highlights about the Relationships between Thermal Patterns and Wind Regimes. Adv. Meteorol. 2013, 2013, 1-11. [CrossRef]

8. Alcoforado, M.-J.; Andrade, H.; Lopes, A.; Vasconcelos, J. Application of climatic guidelines to urban planning. The example of Lisbon (Portugal). Landsc. Urban Plan. 2009, 90, 56-65. [CrossRef]

9. Alcoforado, M.-J.; Andrade, H. Nocturnal urban heat island in Lisbon (Portugal): Main features and modelling attempts. Theor. Appl. Clim. 2005, 84, 151-159. [CrossRef]

10. Oke, T.R. The energetic basis of the urban heat island. Q. J. R. Meteorol. Soc. 1982, 108, 1-24. [CrossRef]

11. Oliver, J.E.; Oke, T.R. Boundary Layer Climates. Geogr. Rev. 1979, 69, 486. [CrossRef]

12. Oke, T.R.; Mills, G.; Christen, A.; Voogt, J.A. Urban Climates; Cambridge University Press: Cambridge, UK, 2017.

13. Founda, D.; Santamouris, M. Synergies between Urban Heat Island and Heat Waves in Athens (Greece), during an extremely hot summer (2012). Sci. Rep. 2017, 7, 1-11. [CrossRef]

14. Heaviside, C.; Vardoulakis, S.; Cai, X.-M. Attribution of mortality to the urban heat island during heatwaves in the West Midlands, UK. Environ. Health 2016, 15, 49-59. [CrossRef] [PubMed]

15. Li, D.; Bou-Zeid, E. Synergistic Interactions between Urban Heat Islands and Heat Waves: The Impact in Cities Is Larger than the Sum of Its Parts. J. Appl. Meteorol. Clim. 2013, 52, 2051-2064. [CrossRef] 
16. Ramamurthy, P.; Bou-Zeid, E. Heatwaves and urban heat islands: A comparative analysis of multiple cities. J. Geophys. Res. Atmos. 2017, 122, 168-178. [CrossRef]

17. Tan, J.; Zheng, Y.; Tang, X.; Guo, C.; Li, L.; Song, G.; Zhen, X.; Yuan, D.; Kalkstein, A.J.; Li, F.; et al. The urban heat island and its impact on heat waves and human health in Shanghai. Int. J. Biometeorol. 2009, 54, 75-84. [CrossRef]

18. Zhou, Y.; Shepherd, J.M. Atlanta's urban heat island under extreme heat conditions and potential mitigation strategies. Nat. Hazards 2010, 52, 639-668. [CrossRef]

19. AML. Metropolitan Climate Change Adaptation Plan, Volume I: Definition of the Base Scenario to the AML Adaptation (from the Portuguese Plano Metropolitano de Adaptação às Alterações Climáticas Volume I Definição do Cenário Base de Adaptação Para a AML); AML: Lisbon, Portugal, 2018.

20. Beniston, M.; Stephenson, D.B.; Christensen, O.B.; Ferro, C.A.T.; Frei, C.; Goyette, S.; Halsnaes, K.; Holt, T.; Jylhä, K.; Koffi, B.; et al Future extreme events in European climate: An exploration of regional climate model projections. Clim. Chang. 2007, 81, 71-95. [CrossRef]

21. EEA Climate Change, Impacts and Vulnerability in Europe 2012: An Indicator-Based Report; European Environment Agency: Copenhagen, Denmark, 2012.

22. Santo, F.E.; De Lima, M.I.P.; Ramos, A.M.; Trigo, R.M.; Coelho, M.F.E.S. Trends in seasonal surface air temperature in mainland Portugal, since 1941. Int. J. Clim. 2014, 34, 1814-1837. [CrossRef]

23. Giorgi, F.; Lionello, P. Climate change projections for the Mediterranean region. Glob. Planet. Chang. 2008, 63, 90-104. [CrossRef]

24. Mihalakakou, G.; Santamouris, M.; Papanikolaou, N.; Cartalis, C.; Tsangrassoulis, A. Simulation of the Urban Heat Island Phenomenon in Mediterranean Climates. Pure Appl. Geophys. PAGEOPH 2004, 161, 429-451. [CrossRef]

25. Tolika, K. Assessing Heat Waves over Greece Using the Excess Heat Factor (EHF). Climate 2019, 7, 9. [CrossRef]

26. Buzar, S.; Baigorrotegui, G.; Parker, C.; Estenssoro, F.; Tsilini, V.; Papantoniou, S.; Kolokotsa, D.-D.; Maria, E.-A.; Bouzarovski, S.; Herrero, S.T.; et al. Pobreza Energética en España 2018. Energy Policy 2017. [CrossRef]

27. Gouveia, J.P.; Seixas, J.; Long, G. Mining households' energy data to disclose fuel poverty: Lessons for Southern Europe. J. Clean. Prod. 2018, 178, 534-550. [CrossRef]

28. Thomson, H.; Snell, C.; Liddell, C. Fuel poverty in the European Union: A concept in need of definition? People Place Policy Online 2016, 10, 5-24. [CrossRef]

29. De Ridder, K.; Maiheu, B.; Lauwaet, D.; Daglis, I.A.; Keramitsoglou, I.; Kourtidis, K.; Manunta, P.; Paganini, M. Urban Heat Island Intensification during Hot Spells_-The Case of Paris during the Summer of 2003. Urban Sci. 2016, 1, 3. [CrossRef]

30. D’Ippoliti, D.; Michelozzi, P.; Marino, C.; De’Donato, F.; Menne, B.; Katsouyanni, K.; Kirchmayer, U.; Analitis, A.; Medina-Ramón, M.; Paldy, A.; et al. The impact of heat waves on mortality in 9 European cities: Results from the EuroHEAT project. Environ. Health 2010, 9, 37. [CrossRef]

31. Spinoni, J.; Naumann, G.; Vogt, J.V. Pan-European seasonal trends and recent changes of drought frequency and severity. Glob. Planet. Chang. 2017, 148, 113-130. [CrossRef]

32. Lopes, A.; Oliveira, A.; Correia, E.; Reis, C. Identificação das Ilhas de Calor Urbano e Simulação para as Áreas Críticas da Cidade de Lisboa-Fase 1-Caraterização e Cartografia das Ilhas de Calor Atuais; Câmara Municipal de Lisboa: Lisbon, Portugal, 2020. (In Portuguese)

33. Reis, C.; Lopes, A.; Correia, E.; Fragoso, M. Local Weather Types by Thermal Periods: Deepening the Knowledge about Lisbon's Urban Climate. Atmosphere 2020, 11, 840. [CrossRef]

34. Oke, T.R.; Mills, G.; Christen, A.; Voogt, J.A. Urban Heat Island. In Urban Climates; Cambridge University Press: Cambridge, UK, 2017; pp. 197-237.

35. Gartland, L. Heat Islands; Routhledge: London, UK, 2012; ISBN 9781849771559.

36. Wang, K.; Li, Y.; Wang, Y.; Yang, X. On the asymmetry of the urban daily air temperature cycle. J. Geophys. Res. Atmos. 2017, 122, 5625-5635. [CrossRef]

37. Oliveira, A.; Lopes, A.; Niza, S. Local climate zones datasets from five Southern European cities: Copernicus based classification maps of Athens, Barcelona, Lisbon, Marseille and Naples. Data Br. 2020, 31, 105802. [CrossRef]

38. Oliveira, A.; Lopes, A.; Niza, S. Local Climate Zones in five Southern European cities: An improved GIS-based classification method based on free data from the Copernicus Land Monitoring Service. Urban Clim. 2020, 33, 100631. [CrossRef]

39. Team, A. ASTER Global DEM Validation. Available online: https://lpdaac.usgs.gov/ (accessed on 28 July 2009). [CrossRef]

40. Chapman, L. Assessing topographic exposure. Meteorol. Appl. 2000, 7, 335-340. [CrossRef]

41. Mikita, T.; Klimánek, M. Topographic Exposure and its Practical Applications. J. Landsc. Ecol. 2010, 3, 42-51. [CrossRef]

42. Lott, J.N. The quality control of the integrated surface hourly database. In Proceedings of the Bulletin of the American Meteorological Society; National Climatic Data Center: Asheville, NC, USA, 2004.

43. AEMET; IPMA. Iberian Climate Atlas-Air Temperature and Precipitation (1971-2000); Agencia Estatal de Meteorología (Espanã) and Instituto de Meteorologia (Portugal): Madrid, Spain, 2011; ISBN 9788478370795.

44. Nairn, J.; Fawcett, R. Defining Heatwaves: Heatwave Defined as a Heat-Impact Event Servicing all Community and Business Sectors in Australia; Centre for Australian Weather and Climate Research: Kent Town, Australia, 2013.

45. Perkins, S.E. A review on the scientific understanding of heatwaves-Their measurement, driving mechanisms, and changes at the global scale. Atmos. Res. 2015, 164-165, 242-267. [CrossRef] 
46. Otero, N.; Sillmann, J.; Butler, T. Assessment of an extended version of the Jenkinson-Collison classification on CMIP5 models over Europe. Clim. Dyn. 2017, 50, 1559-1579. [CrossRef]

47. Otero, N. jcext: Extended Classification of Weather Types. Available online: https://cran.r-project.org/\%0Aweb/packages/jcext/ index.html (accessed on 17 October 2019).

48. R Development Core Team. R: A Language and Environment for Statistical Computing; R Foundation for Statistical Computing: Vienna, Austria, 2011; ISBN 3900051070.

49. Sousa, P.M.; Barriopedro, D.; Ramos, A.M.; García-Herrera, R.; Espírito-Santo, F.; Trigo, R.M. Saharan air intrusions as a relevant mechanism for Iberian heatwaves: The record breaking events of August 2018 and June 2019. Weather. Clim. Extremes 2019, 26, 100224. [CrossRef]

50. Bonferroni, C.E. Il Calcolo delle Assicurazioni su Gruppi di Teste. In Studi in Onore del Professore Salvatore Ortu Carboni; Bardi: Rome, Italy, 1935. (In Portuguese)

51. Major, D.C.; Omojola, A.; Dettinger, M.; Hanson, R.T.; Sanchez-Rodriguez, R. Climate Change and Cities: First Assessment Report of the Urban Climate Change Research Network; Cambridge University Press: New York, NY, USA, 2011. [CrossRef]

52. Jiang, P.; Liu, X.; Zhu, H.; Li, Y. Features of Urban Heat Island in Mountainous Chongqing from a Dense Surface Monitoring Network. Atmosphere 2019, 10, 67. [CrossRef]

53. Basara, J.B.; Hall, P.K.; Schroeder, A.J.; Illston, B.G.; Nemunaitis, K.L. Diurnal cycle of the Oklahoma City urban heat island. J. Geophys. Res. Space Phys. 2008, 113. [CrossRef]

54. Camilloni, I.; Barrucand, M. Temporal variability of the Buenos Aires, Argentina, urban heat island. Theor. Appl. Climatol. 2012, 107, 47-58. [CrossRef]

55. Lopes, A.; Saraiva, J.; Alcoforado, M.J. Urban boundary layer wind speed reduction in summer due to urban growth and environmental consequences in Lisbon. Environ. Model. Softw. 2011, 26, 241-243. [CrossRef]

56. Jiang, S.; Lee, X.; Wang, J.; Wang, K. Amplified Urban Heat Islands during Heat Wave Periods. J. Geophys. Res. Atmos. 2019, 124, 7797-7812. [CrossRef]

57. Richard, Y.; Pohl, B.; Rega, M.; Pergaud, J.; Thevenin, T.; Emery, J.; Dudek, J.; Vairet, T.; Zito, S.; Chateau-Smith, C. Is Urban Heat Island intensity higher during hot spells and heat waves (Dijon, France, 2014-2019)? Urban Clim. 2021, 35, 100747. [CrossRef]

58. Anderson, V.; Leung, A.C.W.; Mehdipoor, H.; Jänicke, B.; Milošević, D.; Oliveira, A.; Manavvi, S.; Kabano, P.; Dzyuban, Y.; Aguilar, R.; et al. Technological opportunities for sensing of the health effects of weather and climate change: A state-of-the-art-review. Int. J. Biometeorol. 2021, 1-25. [CrossRef]

59. Scherer, D.; Fehrenbach, U.; Beha, H.-D.; Parlow, E. Improved concepts and methods in analysis and evaluation of the urban climate for optimizing urban planning processes. Atmos. Environ. 1999, 33, 4185-4193. [CrossRef]

60. Ren, C.; Ng, E.Y.-Y.; Katzschner, L. Urban climatic map studies: A review. Int. J. Clim. 2010, 31, 2213-2233. [CrossRef] 